Editorial

\title{
Genetic Screening of Cervical Cancer
}

Ciro Comparetto ${ }^{1,+, *}$, Franco Borruto ${ }^{2,+}$

1. Division of Obstetrics and Gynecology, San Paolo Private Clinic, Via Bonellina 199, 51100 Pistoia, Italy; E-Mail: cicomp@tin.it

2. Consultant in Public Health, Department of Social Affairs, Principality of Monaco; E-Mail: fborruto@libello.com

+ These authors contributed equally to this work.

* Correspondence: Ciro Comparetto; E-Mail: cicomp@tin.it

Special Issue: Genetic Screening of Cervical Cancer

OBM Genetics

2021, volume 5, issue 3

doi:10.21926/obm.genet.2103132
Received: June 29, 2021

Accepted: June 30, 2021

Published: July 19, 2021

\begin{abstract}
Medical genetics plays an important role in the screening and prevention of numerous diseases. Thus, it is important to develop effective screening and prevention programs and improve the assessment of the susceptibility of diseases. The development of screening and prevention programs depends on the identification of early biomarkers (including functional and behavioral) for the risk and onset of the disease, and such programs need to be designed according to internationally accepted criteria. Cervical cancer represents a very relevant disease from the health and social perspective; around 528,000 new cases are diagnosed every year globally, of which, $85 \%$ are from developing countries, representing almost $12 \%$ of all cancers in females. Substantial reductions in the incidence of and mortality from cervical cancer have been observed after the introduction of prevention campaigns with the implementation of cervical screening programs through Papanicolaou (Pap) tests and, in particular, following the introduction of organized programs which guarantee a high level of screening coverage, as well as, the quality and continuity of diagnostic-therapeutic procedures. It is estimated that Pap smear screening every 3-5 years provides $80 \%$ protection against the onset of cancer. Advances in diagnostic techniques, particularly the development
\end{abstract}

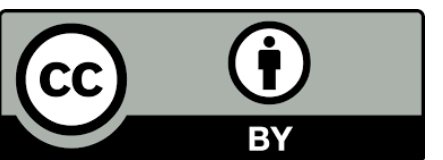

(C) 2021 by the author. This is an open access article distributed under the conditions of the Creative Commons by Attribution License, which permits unrestricted use, distribution, and reproduction in any medium or format, provided the original work is correctly cited. 
of easy-to-use molecular genetic tests, are replacing the use of the established Pap smear as a screening tool. This is possible owing to the discovery in 1975 that some cellular morphological changes (koilocytosis) were related to the presence of a Human Papillomavirus (HPV) infection. The HPV test is performed on a small sample of cells taken from the cervix, similar to the Pap test; however, it is not a morphological exam but a molecular biology exam that detects the presence of HPV by identifying its deoxyribonucleic acid (DNA) or messenger ribonucleic acid (mRNA). The results of numerous experimental studies have demonstrated a greater sensitivity of this test compared to the sensitivity of the traditional Pap test. However, the HPV test has a lower specificity due to two main factors: 1) The HPV test is based on the search for the types of viruses that have a greater oncogenic potential, and 2) It does not discriminate between transient infections and persistent and productive infections. The most widely used molecular tests are based on the search for HPV sequences and genotyping using molecular biology techniques, such as direct hybridization, qualitative polymerase chain reaction $(\mathrm{PCR})$, and viral nucleotide sequencing.

\section{Keywords}

Cervical cancer; genetics; screening; prevention; Human Papillomavirus; molecular biology; Pap smear; koilocytosis; biomarkers

\section{Introduction}

Advances in "genomic medicine" in developed countries are driving a notable expansion of preventive medicine based on population screening to determine individual susceptibility to common diseases, including heart disease, diabetes, cancer, and progressive neurodegenerative diseases. The identification of the people at risk can be followed by the application of primary prevention, for example, through dietary measures, specific physical exercises, and/or secondary prevention through pharmacological interventions. In recent years, owing to the considerable progress in the field of molecular genetics, a debate has arisen on the suitability of conducting population screening to identify, through mutational analysis in the preclinical phase, subjects suffering from dominant autosomal diseases of adult-onset, including familial hypercholesterolemia, myotonic dystrophy, Huntington's chorea, hereditary adult-type polycystic kidney, hereditary hemochromatosis, and thrombophilia due to the heterozygous state for Factor V Leiden defect [1]. The most important developments during this period were in the areas of gynecological cancer genetics and tumor growth control factors. In this field, new technologies are being developed that could lead to gynecological cancer therapies at the genetic or cellular level. The quest for the best non-cervical gynecological cancer screening tests continues. Imaging methods, such as magnetic resonance imaging (MRI), have advanced to the point that they can now provide very highresolution pictures of cancers in vivo, but this technology is quite expensive [2].

The rich, multidisciplinary history of cancer prevention started in the 1700s with surgical and occupational advice and ended in 2009 with the results of the massive Selenium and Vitamin E (prostate) Cancer Prevention Trial (SELECT) (35,535 men). This timeline is a fascinating collection of preclinical and clinical chemopreventive, vaccine, medical, and behavioral studies. The studies in 
mice by Lathrop and Loeb in 1913 and 1916 on cancer growth associated with pregnancy [3], or the studies on cancer prevention by castration (oophorectomy), prevention of chemically induced mouse carcinogenesis in 1929 [4], energy restriction studies in the 1940s [5-7], and later, the molecular characterization of cancerization [8,9] are all preclinical landmarks in cancer prevention. In 2009, researchers focused on the effects of angiogenesis inhibition, as well as multistep carcinogenesis in genetically engineered mice. Numerous large and small chemoprevention studies of nutritional supplements [10], other dietary approaches [11], the Bacillus Calmette-Guérin (BCG) trial in 1976 [12], molecular-targeted agents [13], and agents to avoid infection-related cancers [14] are some examples among many clinical trials. In 1984, a vaccine against the Hepatitis B Virus (HBV) was developed to prevent liver cancer. The removal of cervical intraepithelial neoplasia (CIN) found by screening, including Papanicolaou (Pap) testing introduced in 1929 and colposcopy for cervical premalignancy [15], colonoscopy and polypectomy to prevent colorectal cancer initiated in the 1960s [16], and prophylactic procedures, such as in Lynch syndrome patients started in 1977 [1721], are examples of clinical, surgical prevention. Smoking cessation and regulation (that dates back to the 1950s), obesity control (that dates back to 1841), and research on gene therapy and cancer survivorship are all examples of behavioral studies [22].

Medical ethics has been an undisputed aspect of medical research in recent years. Many people claim that modern medical developments, such as the invention of dialysis machines, respirators, $\mathrm{MRI}$, genetic testing, and various cancer screenings, are to blame for the bio-ethical dilemmas that physicians face in the $21^{\text {st }}$ century [23]. Until recently, debates over the study and screening ethics revolved around two interconnected issues: the voluntary and informed consent of participants and the proper relationship between the risk and gain to subjects in the experiment. Patients have the right to know everything about their medical condition. This legal concept emerged initially as a result of court rulings on informed consent, but over time, physicians realized that most patients want to learn the truth about their condition to make informed decisions. To screen is to search for diseases in the absence of symptoms or to try to find diseases without the knowledge of their presence. Routine mammography to detect breast cancer, Pap smears to detect cervical cancer, or prostate-specific antigen (PSA) testing to detect prostate cancer are all examples of screening. The key goal of the ethical concepts in cancer screening programs is to avoid causing undue harm to the people who participate. The practice of disease screening may pose several ethical concerns [24, 25].

\section{Genetic Screening}

\subsection{Overview}

Genetic screening is a process that aims to identify individuals whose genetic constitution (genotype) is a determining or predisposing cause of disease in the individual being screened and/or in their descendants. Depending on the target population, genetic screenings are divided into prenatal, neonatal, and adulthood, and can include the whole population or a specific subpopulation. This methodology is different from other types of medical screening since in this case, the identification of a subject at risk has significant implications not only for the person concerned but also for the family members of the individual being screened, who, among other things, have not asked to determine their genetic constitution and may not be interested in knowing it. Genetic screening, alongside benefits, can have negative effects. The main benefits of genetic 
screening include the diagnosis of a presymptomatic disease or a predisposition to a genetic disease, the determination of a predisposition to negative effects due to environmental factors (e.g., drugs, smoking, and diet), and the identification of the status of a healthy carrier of a genetic disease, with implications for the risks of reproduction [26]. The possible negative effects are psychological repercussions, including anxiety, loss of self-esteem, and a sense of guilt, and are closely related to the information received, mostly due to the difficulties in understanding and interpreting the genetic consultation [27]. In this context, the improper use of information related to the facts highlighted through this method could be the cause of various forms of social stigmatization and marginalization, and discrimination in the workplace, which can ultimately cause significant economic damage in employment, as well as at the insurance level. Genetic screening is, therefore, an extremely sensitive medical step, from a social perspective, for the success of which the following conditions must be met - rationality of design, benefit outweighing potential harm, acceptance by the target population, feasibility, prevalence of benefits over costs, education of the population, adequately equipped laboratories, previously successful pilot programs, importance and seriousness of the disease, inclusion of screening in the public health system, development of adequate ability to longitudinally follow the identified subjects, specificity and sensitivity of the selected tests, voluntary participation, pre-test and post-test genetic consultation, informed consent (this may not be necessary if the analysis is essential for the life and health of the subject being screened), and absolute confidentiality [27]. Any use of the blood samples collected for screening purposes, other than the purposes agreed to, requires specific additional informed consent. Blood samples must be stored in a way that the same confidentiality that is commonly used for each medical procedure is guaranteed.

\subsection{Prenatal Screening}

Prenatal screening consists of the identification of genetic diseases in the prenatal period through various methods, including ultrasound study of the fetus, analysis of maternal serum for risk factors, examination of fetal cells obtained through amniocentesis or chorionic villus sampling (CVS), analysis of fetal cells in the maternal blood, and preimplantation embryo analysis. In particular, prenatal screening is currently directed to [28]:

1. The identification of numerous congenital malformations using ultrasounds.

2. The identification of women at risk of Down syndrome and other chromosomal aberrations through ultrasound assessment of nuchal translucency (NT) and measurement of various biochemical parameters in the mother's blood, including beta-human chorionic gonadotropin ( $\beta$ hCG) and pregnancy-associated plasma protein A (PAPP-A) in the first trimester and alphafetoprotein $(\alpha-F P)$, total hCG, unconjugated estriol, and inhibin in the second trimester.

3. The determination of the risk of neural tube defects (NTD) using ultrasounds and $\alpha$-FP measurements [29-35].

\subsection{Neonatal Screening}

Neonatal screening is aimed at identifying genetic diseases, especially metabolic and endocrine problems, to determine which treatment can prevent the clinical development of the disease. Neonatal diseases currently being screened by unanimous consent [36] are phenylketonuria (PKU), congenital hypothyroidism, congenital deafness, and sickle cell anemia (SCA). The topic of debate is 
the screening of other metabolic disorders, which include cystic fibrosis, congenital adrenal hyperplasia (CAH), mental insufficiency linked to Fragile $X$ syndrome, and the glucose-6-phosphate dehydrogenase (G6PD) defect (Table 1) [37-40].

Table 1 List of genetic diseases for which neonatal screening is recommended.

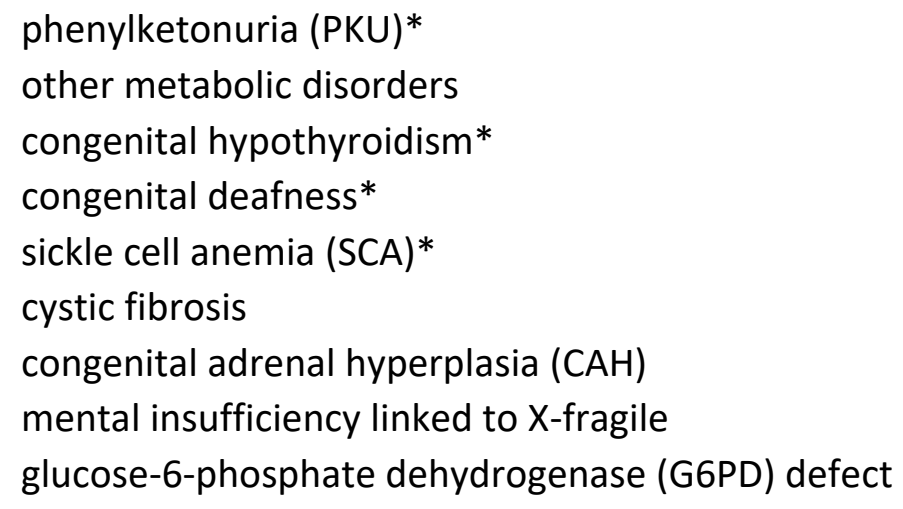

\section{* always}

\subsection{Adulthood Screening}

Genetic screening in adulthood includes [41]:

1. The identification of the carrier status of an autosomal recessive or X-linked disease to prevent the development of the disease in descendants, by either screening the whole population or by cascade screening after the identification of an index case; the diseases currently being screened in the populations at risk are Tay-Sachs disease, $\alpha$-and $\beta$-thalassemia, SCA, and cystic fibrosis.

2. The identification of adult-onset dominant diseases or hereditary cancers in subpopulations at risk. The adult-onset diseases under scrutiny on whether to include them in screening programs include familial hypercholesterolemia, myotonic dystrophy, Huntington's chorea, polycystic kidney, hereditary hemochromatosis, Leiden factor heterozygosity thrombophilia, and $\alpha$-antitrypsin (AAT) defect. The most common hereditary conditions considered as cancer-related risks in screening programs are ataxia-telangiectasia, Cowden's disease, familial adenomatous polyposis (FAP), familial gastric cancer, Gorlin's syndrome, hereditary ovarian and breast cancer, hereditary nonpolyposis colorectal cancer (HNPCC), familial melanoma, Li Fraumeni syndrome, hereditary prostate cancer (HPC), type 1, type $2 \mathrm{a}$, and type $2 \mathrm{~b}$ multiple endocrine neoplasms (MEN), type 1 and type 2 neurofibromatosis (NF), retinoblastoma (RB), and Peutz-Jeghers and Von Hippel-Lindau (VHL) syndromes (Table 2).

3. The determination of the predisposition to the development of polyfactorial diseases such as coronary heart disease (CHD), type I and type II diabetes mellitus, allergic asthma, arterial hypertension, cardiovascular disease (CVD), inflammatory bowel disease (IBD), rheumatoid arthritis, systemic lupus erythematosus (SLE), and various psychiatric diseases, and/or negative side effects by the administration of specific drugs [42-43]. 
Table 2 List of hereditary conditions associated with the risk of developing cancer.

\begin{tabular}{|c|c|c|}
\hline Syndrome & Predominant cancer & Gene \\
\hline ataxia-telangiectasia & breast cancer, lymphoma & ataxia-telangiectasia mutated (ATM) \\
\hline Cowden's disease & $\begin{array}{l}\text { skin and mucous membranes hamartomas, breast, } \\
\text { thyroid, and renal cell cancer }\end{array}$ & phosphatase and tensin homolog (PTEN) \\
\hline familial adenomatous polyposis (FAP) & colorectal multiple adenomas, colorectal cancer & adenomatous polyposis coli (APC) \\
\hline familial gastric cancer & gastric cancer & cadherin-1 (CDH1) \\
\hline Gorlin's syndrome & nevoid basal cell carcinoma (NBCC) & NBCC syndrome (NBCCS) \\
\hline hereditary ovarian and breast cancer & ovarian, breast, and prostate cancer & $\begin{array}{l}\text { breast cancer } 1 \text { (BRCA1) } \\
\text { BRCA2 }\end{array}$ \\
\hline $\begin{array}{l}\text { hereditary nonpolyposis colorectal } \\
\text { cancer (HNPCC) }\end{array}$ & colorectal, endometrial, ovarian, and gastric cancer & $\begin{array}{l}\text { human mutS homolog } 2 \text { (hMSH2) } \\
\text { human mutL homolog } 1 \text { (hMLH1) } \\
\text { human post-meiotic segregation1 (hPMS1) } \\
\text { hPMS2 } \\
\text { hMSH6 }\end{array}$ \\
\hline familial melanoma & melanoma, glioblastoma, lung cancer & $\begin{array}{l}\text { kinase inhibitor 4A (INK4A)/multiple tumor } \\
\text { suppressor } 1(\mathrm{MTS}-1) \text { /cyclin-dependent kinase } \\
\text { inhibitor 2a (CDKN2A) (P16) }\end{array}$ \\
\hline Li Fraumeni syndrome & $\begin{array}{l}\text { leukemia, soft tissues sarcoma, osteosarcoma, brain } \\
\text { cancer }\end{array}$ & tumor protein 53 (TP53) \\
\hline hereditary prostate cancer (HPC) & prostate cancer & $\begin{array}{l}\text { HPC1 } \\
\text { HPC X-Linked (XPCX) }\end{array}$ \\
\hline 1.. & & \\
\hline
\end{tabular}


type 1

MEN type $2 a$

MEN type $2 b$

neurofibromatosis (NF) type 1

NF type 2

Peutz-Jeghers syndrome

retinoblastoma $(\mathrm{RB})$

Von Hippel-Lindau (VHL) syndrome cancer

medullary thyroid carcinoma (MTC), rearranged during transfection (RET)
pheochromocytoma

MTC

RET

multiple peripheral neurofibromas, optic glioma, NF1

neurofibrosarcoma

central schwannoma, meningiomas, acoustic NF2

neuroma

gastric and intestinal polyps, colorectal, pancreatic, and ovarian cancer

serine/threonine kinase 11 (STK11)

$\mathrm{RB}$, osteosarcoma

RB

renal cell carcinoma, pheochromocytoma, hemangioblastoma 
Genetic screening for these applications requires new recommendations and evaluations, especially as cost/benefit ratios. In the future, informed consent obtained after extensive genetic consultation will be even more relevant. Specific recommendations include the screening of children and adolescents, which, according to the recommendations of the American Academy of Pediatrics (AAP) (1992), can be performed only in the following conditions: immediate clinical benefit to the child or adolescent with the possibility of establishing measures to prevent the disease or its consequences in the individual and to delay the onset or limit the severity of the disease, and benefit other family members, provided there are no adverse effects on the child [44, 45].

Recently, through genomic association studies, with the same type of mutational analysis or with association analysis between disease and deoxyribonucleic acid (DNA) polymorphisms - short DNA segments repeated in tandem with a variable number of repeats in each individual (microsatellites) or polymorphic variations of a single nucleotide called single nucleotide polymorphism (SNP) - it is also possible to identify nucleotide variations in genes. Such mutations lead to a genetic predisposition to the development of common complex polyfactorial diseases (due to the interaction between different genes and environmental factors), including CHD, type I and type II diabetes mellitus, allergic asthma, arterial hypertension, cerebrovascular diseases, chronic IBD, rheumatoid arthritis, SLE, and various psychiatric diseases (e.g., schizophrenia and bipolar syndrome) [46]. The problem is extremely complex, since for each disease, there are variations in the sequence of a large number of genes (probably about 80-100 for each disease) which, when present together, produce the disease only under the influence of certain environmental conditions (e.g., smoking, incorrect diet, lack of physical activities, etc.) [47]. From a technological point of view, there are no obstacles to the development of this type of screening since microarray technology allows the study of numerous nucleotide variations in the genome with relative ease. It is reasonable to assume that this type of screening is likely to be applied soon on a large scale. For these applications, however, informed consent will be required after extensive and careful genetic consultation. Screenings similar to those outlined above are likely to be developed in the future to highlight $a$ priori the possibility of a positive response of each individual to a specific therapy, as well as the possibility of adverse reactions. This approach could lead to the development of personalized medicine [48].

Population-wide screening, to identify healthy (heterozygote) carriers of autosomal recessive diseases, helps to determine couples at risk, where both members are carriers, and therefore, at risk of producing the disease in $25 \%$ of their children. The universally accepted criteria for applying this type of screening to determine a disease are [49]:

1. Frequent, severe disease, for which there is no cure

2. Availability of simple methods to correctly identify healthy carriers

3. Existence of reproductive alternatives for couples at risk

Population-wide screening has so far been conducted for Tay-Sachs disease, $\alpha$-and $\beta$-thalassemia, SCA, and cystic fibrosis. Recently, the inclusion of spinal muscular atrophy (SMA) has been proposed, in which the frequency of a carrier in the population is $1 / 50[50,51]$. The above-mentioned screening programs have been effective, as they have led to conscious and informed procreation in the consulted couples, with a consequent reduction in the number of affected homozygotes. The screening programs for Tay-Sachs disease in Jewish communities and those for $\beta$-thalassemia in the Italian, Greek, and Cypriot communities at risk have particularly been effective [52]. For the success 
of these screening programs, the following requirements can be considered useful and necessary [52]:

1. The identification of the ideal target population, consisting of couples of reproductive age before pregnancy, makes it possible to use different preventive approaches.

2. The voluntary screening of heterozygotes, conducted after obtaining informed consent, following genetic consultation.

3. Educational programs for physicians and paramedics of the screened population and for high school pupils, among whom conducting this type of screening is controversial.

4. The dissemination of information at important sites (e.g., physicians' offices and marriage and family planning offices) through materials (posters and brochures) containing fundamental messages on the characteristics of the disease and the methods of prevention.

5. The efficiency of the technical screening process, to avoid inconclusive examinations, as much as possible, to prevent or reduce anxiety.

6. Recognition of the crucial role of genetic consultation in screening programs. It must be nondirective and based on confidential meetings with the couple and/or the individual bearer. The essential elements to discuss during genetic consultation include the natural history of the disease, available treatments, prognosis, research perspectives, and information on available options (terminate the relationship, maintain the relationship without conceiving, use of prenatal, preconceptional, or preimplantation diagnosis, and in vitro insemination from healthy donors). Accurate information on the risks and benefits must be provided for these different technologies.

7. The need to inform relatives about the risk, once a carrier of an autosomal recessive disease has been identified. This information must be communicated by the identified bearer.

8. The ongoing critical review of the heterozygote screening programs.

9. The need to disseminate these programs in developing countries. This is particularly valid for $\beta$-thalassemia and SCA, which are extremely frequent in such places.

\section{Cancer Genetics}

Cancer affects more people than any other disease. About half of the world's population is likely to get diagnosed with cancer during their lifetime [53]. Cancer is one of the most complex and widespread pathologies in the current clinical epidemiological panorama. The complexity of oncological pathology depends on some biological and clinical characteristics peculiar to malignant tumors, such as multifactorial etiology, biological heterogeneity, variability of clinical manifestations, and natural history of the disease. Also, the complexity is related to the extreme diversification of the response to different treatments, in particular, to medical therapy, due to the histological type and biomolecular properties, the site of onset of the neoplasm, and the severity of health, psychological, and social issues raised by the recognition of the disease and its progress towards chronicity or towards the terminal phase. Disease spread is also a quantitative datum, which, like biological and clinical complexity, places the need for cancer control among the top priorities in the field of health protection.

In recent years, research has shown that cancer development is determined by the altered function of one or more oncogenes (favoring tumor development) and/or of tumor suppressors (inhibiting tumor development) [54]. High-risk population or subpopulation screening for the identification of carriers of cancer-predisposing genes is a future possibility that is already under 
debate. Currently, the search for cancer predisposition is limited to families showing at least one patient with hereditary cancer. The possibility of the existence of a predisposition to the development of hereditary cancer in a family is suggested by the presence of the following conditions in one or more members [55]:

1. The onset of cancer at an unusually young age for that type of tumor

2. Bilateral or multifocal development in a single organ

3. The development of several types of primary tumors in one individual

4. The development of cancer in an individual or in a family in which there are members with congenital anomalies

5. Families in which an inherited cancer-causing mutation has already been identified

Hereditary cancers are due to mutations in specific genes. Mutational analysis of genes implicated in the development of tumors can be performed to diagnose hereditary cancer in an affected individual and/or to find family members at risk after identifying a specific mutation in a relative. As with other hereditary diseases, the study of family members must be preceded by a thorough genetic consultation, illustrating the advantages (application of preventive methods) and disadvantages (stigmatization and loss of self-esteem). It is necessary to acquire informed consent that illustrates several crucial points, providing information on the type of test, the implications of a positive/negative result, the possibility that the test is not informative, the risk of transmission of the defect, and the possibility of psychosocial repercussions. For studies involving children and adolescents, the above considerations apply to late-onset hereditary diseases. Screening of children and adolescents should be limited to early-onset pediatric cancers, such as RB and polyposis/colorectal cancer [56-58]. In the last 25 years, advances in molecular genetics have made genetic testing of inherited mutations in cancer-predisposing genes possible. The exact cellular role of these genes, as well as their carcinogenic potential, are still unknown. Inherited genetic mutations play a significant role in the polygenic and multifactorial nature of cancer in just $5-20 \%$ of cases. Of clinical importance is the identification of hereditary cancer syndromes, predictive genetic testing, and counseling of women and family members at elevated risk. Presymptomatic screening tests and appropriate programs for early cancer detection, prevention, and clinical follow-up are still being debated [59].

Gynecological cancers, which mostly include uterine, ovarian, and cervical cancers, account for 95,000 new cases in the United States (US) annually [60]. The most prevalent cancer is uterine cancer, and the number of new cases and deaths has been due to that. Cervical cancer has declined as a result of preinvasive cancer screening, early detection, and treatment. Ovarian cancer, on the other hand, remains the most fatal cancer due to diagnosis at an advanced stage and drug resistance. At presentation, uterine and cervical cancers are often located in the primary organ, while ovarian cancer is disseminated in the peritoneum and upper abdomen. Surgery is usually the first line of treatment for ovarian cancer, followed by systemic therapy for more advanced cases. Systemic chemotherapy, which includes platinum, taxanes, doxorubicin, topotecan, and gemcitabine, was previously the gold standard in either the upfront or recurrent environment. Over the last three years, molecular and genetic breakthroughs have resulted in the approval of over eight new indications and five novel biological therapies, including antiangiogenics, poly-adenosine diphosphate (ADP)-ribose polymerase (PARP) inhibitors, and immune-therapies [60]. Hereditary syndromes cause $10 \%$ of all gynecological cancers, with hereditary breast-ovarian cancer and hereditary nonpolyposis colon cancer syndromes, also known as HBOC and Lynch syndromes, 
respectively posing the greatest risk [61]. Both lead to ovarian cancer and predispose individuals to endometrial cancer. The Cowden syndrome is linked to endometrial cancer, and Peutz-Jeghers syndrome is linked to an elevated risk of ovarian, uterine, and cervical cancers, while Li-Fraumeni syndrome patients are more likely to develop ovarian and endometrial cancers. Although these syndromes are all linked to gynecological cancers, it is still unclear if these tumors have any epidemiological, clinical, pathological, or imaging characteristics that might allow intervening physicians to suspect a hereditary syndrome in patients with no established genetic risks. Furthermore, both the screening and monitoring systems are fraught with controversy. The ovarian high-grade serous carcinoma (HGSC) that occurs in the fallopian fimbriae is the most common cause of HBOC syndrome [62]. Endometrial tumors associated with Lynch syndrome have a wide range of histological characteristics and a preference for the lower uterine section. The majority of ovarian cancers linked to Lynch and Cowden syndromes are non-serous, typically endometrioid. PeutzJeghers syndrome is closely linked to the ovarian sex cord tumor with annular tubules (SCTAT) and cervical adenoma malignum. Hereditary gynecological tumors, unfortunately, do not seem to have distinguishing imaging characteristics [63]. The appropriate use of tumor markers in patients with gynecological cancers might have a significant effect on disease management. Outside clinical trials, their value in ovarian cancer screening cannot be recommended. Increased levels of different markers may provide prognostic information for patients with early ovarian or cervical carcinoma, which may change their treatment options. The primary utility of tumor markers is in tracking treatment response and confirming relapse, for which they can outperform scans [64-67].

\section{Genetic Screening}

\subsection{Overview}

Despite uterine cervical cancer being considered a preventable disease, it remains the second most common malignancy in women worldwide, with a higher incidence in underdeveloped countries [68]. Cervical cancer represents a very relevant disease from a health and social perspective. Around 528,000 new cases are diagnosed every year globally and, of these, $85 \%$ are from developing countries, where it represents almost $12 \%$ of all female cancers [69]. Data from the National Cancer Registries show that, in Italy, cervical cancer incidence and mortality from 1980 to 2015 have continuously decreased [70]. Mortality from uterine cancer decreased by more than $50 \%$ in the last 40 years, going from 14 cases per 100,000 women in 1955 to 6 cases (with two deaths) per year for every 100,000 women in 1990. Data from the Italian National Statistics Institute (ISTAT) do not differentiate between deaths attributable to cervical cancer or endometrial carcinoma. However, information from population analyses, taking birth cohorts into account, allow approximate differentiation between the two types of cancer, as cervical cancer has an earlier onset than endometrial cancer [71]. The reduction in mortality was observed mainly for the younger cohorts, indirectly suggesting that much of it was due to decreased mortality from cervical cancer. It is currently estimated that, in Italy, about 3,600 new cases of cervical cancer are diagnosed annually, with at least 1,700 registered deaths [72].

Epidemiological studies conducted at the beginning of the second half of the $20^{\text {th }}$ century showed that cervical cancer was infectious and was transmitted by sexual intercourse [73]. For around 15 years, herpes simplex virus type 2 (HSV2), the genital herpes virus, was suspected to be the etiological agent. This hypothesis was disproved just when the first convincing evidence was 
produced that the Human Papillomavirus (HPV) was the causative agent of cervical cancer (99.7\% of cases) [74]. Many findings from the 1980s and 1990s unequivocally confirmed that HPV was the causative agent [75]. The most dangerous type of HPV, among over 100 HPV types, are the types 16 and 18 , which together account for over $70 \%$ of cervical cancer cases and, very likely, for most of the other malignancies of the anogenital region and the oropharynx [76]. HPV infections are a leading cause of virus-associated cancers of the anogenital, oropharyngeal, and cutaneous epithelium [76]. HPV is necessary for the development of cervical neoplasia. Progress in our understanding of the epithelial biology of this common pathogen has greatly influenced current concepts of cervical carcinogenesis. This knowledge has provided a framework for understanding the biological basis of many diagnostic criteria. Furthermore, classification schemes, diagnostic testing, and clinical management have been modified and clarified in light of this knowledge [77]. As a DNA virus, HPV type 16 has a relatively stable genome that is hypothesized to have co-evolved with its host over the millennia [78]. Nevertheless, among the "wild" populations of HPV-16 that are in circulation, a large number of variants have been identified, and these may have considerably different pathogenic potentials [79].

HPV is mainly transmitted by sexual contact and is detected in over $99 \%$ of cases of cervical cancer. While most women will become infected during their sexual lives, only a small percentage of those infected will develop cancer [80]. Therefore, HPV infection is not enough to trigger malignant transformation; other important co-factors play a role in the multistep phase of tumor formation. The long gap between primary infection and cancer emergence indicates that other environmental and host factors, such as sexual activity, immune status, genetic predisposition, nutritional status, tobacco use, and socioeconomic status, are involved in tumor formation. However, in the absence of HPV, these co-factors are irrelevant. In the screening and diagnosis of cervical neoplastic lesions, Pap testing (Pap smear) and HPV DNA testing are used. In the prevention of HPV infection, HPV vaccination tends to be cost-effective. The development of sophisticated targeted therapeutic approaches, such as antisense oligonucleotides against HPV oncoproteins, could benefit from a detailed understanding of the mechanisms that underpin HPV carcinogenesis [81]. Cervical cancer has an inherited aspect, which is linked to genetic vulnerability, according to recent population-based twin and family studies [82]. As a result, SNP markers and microsatellites should be considered when assessing the genetic factors involved in precancerous changes in cervical cancer. Combinations of genetic factors, such as SNPs and microsatellites, can influence the risk associated with complex multifactorial diseases, such as cervical cancer, according to some studies [83-84].

HPV infects epithelial cells in the cervix's transition region. HPV infection is most common in young people, similar to other sexually transmitted diseases (STDs). However, since most people develop an efficient type-specific immune response, this viral infection is usually temporary. Genital warts affect about $1 \%$ of the population, and cervical precancerous lesions affect $4 \%$ of women, which may be low-grade squamous intraepithelial lesion (L-SIL) or high-grade SIL (H-SIL) [85]. These lesions, which are most often seen in women between the ages of 35 and 40 , have a high chance of progressing to invasive cancer. HPV DNA inclusion into the host genome and overexpression of viral "early" oncogenes (E6 and E7) results in the formation of premalignant and malignant cells. By avoiding the growth control exerted by tumor protein 53 (TP53) and RB protein 105, cells gain a proliferative advantage (p105Rb). Both cellular proteins are inactivated by E6 and E7 proteins, respectively. Aneuploidy and karyotypic anomalies are also important occurrences in tumor 
development [85]. When high-risk HPV infects the cervical epithelium, it might cause active or transforming cervical intraepithelial neoplasia (CIN) lesions, which can have similar morphology. Aberrations in host cell genes accumulate over time in transforming CIN lesions, which is necessary for cancer progression. Early and advanced transforming CIN lesions can be differentiated based on epigenetic changes. This paves the way for new molecular methods for the screening, diagnosis, and management of the precursor lesions in cervical cancer $[86,87]$. Thus, testing of molecular targeted therapies against this malignancy is highly desirable. The development of cervical cancer is a multistep process that begins with the accumulation of genetic and epigenetic changes in regulatory genes, which leads to oncogene activation and the inactivation or loss of tumor suppressor genes (TSGs). In the last decade, epigenetic inactivation of TSGs by promoter hypermethylation had been recognized as a significant and alternative mechanism in the genesis of tumors besides genetic alterations. Epigenetic changes in cervical cancer can affect the expression of HPV and host genes at different stages in the multistep carcinogenesis process [88]. Several epigenetic changes occur in HPV and host cellular genomes during cervical carcinogenesis, including global DNA hypomethylation [89], hypermethylation of the core TSGs [90], and histone modifications [91]. Epigenetic modifications are reversible, making them a priority for transcriptional therapies, including DNA methylation and histone deacetylase inhibition. To date, studies in patients with cervical cancer have shown that demethylation and histone deacetylase inhibition can reactivate the expression of hypermethylated and silenced TSGs, as well as, the hyperacetylation and inhibitory effect on histone deacetylase activity in tumors [92]. Furthermore, the identification of epigenetic changes in cytological smears, serum DNA, and peripheral blood could lead to the creation of new biomolecular markers for early detection, response prediction, and prognosis $[93,94]$. In cervical carcinogenesis, DNA methylation is an early and common molecular alteration. During cervical carcinogenesis, methylation of the HPV long control region (LCR) and "late" gene (L1) is normal, and it increases with the severity of cervical neoplasm. In invasive cervical cancers, the L1 gene of HPV-16 and HPV-18 are repeatedly hypermethylated, which could be used as a clinical marker of cancer progression [95-99]. Furthermore, in cervical precursors and invasive cancers, promoters of TSGs involved in many cellular pathways are methylated. Some of them are linked to squamous cell carcinomas (SCC), while others are linked to adenocarcinomas, L-SIL, or atypical squamous cells of unknown significance (ASC-US). For this methodology to be clinically applied, however, consistent panels must be validated. Demethylating drugs can even be used to revert methylated TSGs, which might be an alternative anticancer therapy. However, demethylating drugs with no carcinogenic or mutagenic properties must be detected and confirmed first [100].

The pathogenesis mechanisms of cervical cancer are not well understood currently. As mentioned earlier, the inactivation of TSGs and activation of oncogenes have been shown to play a role in carcinogenesis induced by genetic and epigenetic changes. Previously, it was widely assumed that genetic mutations, especially somatic mutations in TSGs, were key events in tumor pathogenesis. With a better understanding of tumors in recent years, evidence has shown that aberrant hypermethylation of 5'-cytosine (C)- phosphate (p)-G (guanine)-3' (CpG islands or CGI) in promoters causes epigenetic silencing of certain genes [101]. Carcinogenesis and metastasis are also aided by histone alteration. Rather than variations in DNA sequences, epigenetics applies to heritable changes in gene expression triggered by regulatory mechanisms. DNA methylation, chromatin remodeling, histone modification, and micro-ribonucleic acid (miRNA) regulation are 
examples of epigenetic processes. These changes, taken together or separately, enable researchers to create methylation profiles, histone modification maps, and expression profiles that are specific to this pathology and can be used as screening, early detection, or prognostic markers in cervical cancer [102]. Understanding the genetic and epigenetic changes linked to the development of cervical cancer may lead to the development of molecular biomarkers that can be used for screening, diagnosis, and treatment of cervical cancer precursor lesions [103]. In invasive cervical cancer (ICC), epigenetic alterations such as dysregulation of miRNA expression are common. The mechanism and function of miRNA dysregulation in cervical carcinogenesis are still unknown. MiR-29a and miR-21 are most commonly downregulated and upregulated in ICC progression, according to studies examining miRNA expression in ICC progression [104-108]. MiR-10a, miR-20b, miR-9, miR-16, and miR-106 have all been found to be dysregulated in microarray-based studies [109-115]. In cervical exfoliated cells, miR-34a, miR-125, and miR-375 were also found to be dysregulated during cancer progression [116-117]. The importance of miRNA in ICC progression and early development is becoming increasingly apparent. Presently, studies are primarily conducted according to convenience, which leads to selection bias, and are often limited in size - these factors restrict our understanding of the role of miRNA in ICC. The use of a tailored approach rather than a genomewide investigation also prevents the detection of all related miRNA. Deep sequencing on large-scale population-based studies will aid in the discovery and validation of the connection between altered miRNA expression and cervical cancer progression, allowing biomarkers to be identified. Small basic miRNA signatures could be used in screening once they have been evaluated using a miRNome scale $[118,119]$.

The existence of a somatic or germline breast cancer (BRCA) mutation is now accepted as a standard of care to select patients with ovarian cancer for treatment with PARP inhibitors. During the clinical development of the PARP inhibitor class of drugs, it was discovered that a subset of women without BRCA mutations responded to them (termed "BRCAness") [120]. Other genetic defects causing homologous recombinant deficiency (HRD) were thought to make BRCA wild-type cancers more susceptible to PARP inhibition [121]. These other causes of HRD are also being studied at the molecular level. Individual gene defects, such as the recombination protein A 51 (RAD51) mutation and the checkpoint kinase 2 (CHEK2) mutation, homozygous somatic failure, and wholegenome properties such as genomic scarring are among them. Testing this in patients with ovarian cancer, as well as with endometrial and cervical cancers, is possible when selecting patients for molecular therapy targeting DNA repair. The use of HRD assays and multiple gene sequencing panels to select a larger group of patients for PARP inhibitor therapy is being investigated. Mismatch repair (MMR), checkpoint signaling, and non-homologous end-joining (NHEJ) DNA repair are all non-HRD targets for exploiting DNA repair defects in gynecological cancers [122-125].

The widespread adoption of high-throughput next-generation sequencing (NGS) technologies has allowed for massive parallel tumor tissue sequencing, revealing new information about tumor biology and advancing personalized medicine. In gynecological cancer, a large number of targeted agents have been studied, and some have been approved by the US Food and Drug Administration (FDA), such as PARP inhibitors in ovarian cancer, bevacizumab in ovarian and cervical cancers, and pembrolizumab in microsatellite-unstable or MMR-deficient endometrial cancer. Identification of predictive biomarkers capable of guiding the selection of the appropriate medication for the patient is critical for improving the efficacy of targeted therapy. To promote faster adoption of a genotyping approach in treatment selection, various limitations must be addressed, such as the ability to easily 
evaluate tumor heterogeneity and clonal evolution along disease trajectory, as well as, the need for novel trial designs, such as adaptive or basket trials incorporating molecular features as selection criteria. Detailed examination of the genomic characteristics of exceptional responders could lead to a better understanding of tumor biology, the mechanism of action of a particular target agent, and the discovery of predictive biomarkers for future studies [126].

\subsection{Prevention}

The discovery of high-risk HPV forms as a necessary cause of cervical cancer opens up the possibility of successful primary prevention and increased productivity in cervical screening programs. However, to take advantage of these opportunities, a better understanding of the natural history of HPV infection and its relationship to the development of cervical epithelial abnormalities is needed [127]. Persistent high-risk HPV can progress from a beneficial (virion-producing) to an abortive or transforming infection, with cancer developing as a result of the host's genetic mutations. However, it is uncertain which precancerous lesions advance and which do not; the majority of precancers identified by screening are treated, resulting in overtreatment. Following the discovery of HPV as a carcinogen, successful preventive vaccines and responsive HPV DNA and RNA tests were developed. Vaccination services (the ultimate long-term prevention strategy) and HPV test screening could drastically alter the landscape of HPV-related cancers if used together. Since HPV testing provides more reassurance when the result is negative, it is likely to replace cytologybased cervical screening. However, ensuring that HPV vaccination and screening are implemented effectively around the world remains a challenge [128-131]. One of the most important reasons that explain the variation in the incidence, prevalence, and mortality from cervical cancer across geographical areas is the lack or inefficiency of screening programs. Screening programs can be implemented through:

1. Primary prevention, i.e., vaccination; and

2. Secondary prevention, i.e., Pap smear, thin layer cytology, and HPV testing.

\subsubsection{Primary Prevention}

Primary prevention involves interventions aimed at changing social habits, improving the health and cultural status of women, along with the use of suitable measures to avoid or reduce infection through extensive vaccination programs. Primary prevention is based on the principle that to decrease the risk of a disease, the level of exposure to agents, which either cause the disease or increase the risk to contract it, must be avoided or minimized as much as possible. The results of the primary prevention of chronic degenerative diseases, including cancer, however, may remain unfruitful for a long time, and hence, not quantifiable. This often undermines the importance of primary prevention, especially when the quantitative assessment of the risks and benefits for the comparison of the exposure to specific substances is difficult. While there is no valid reason to believe that the carcinogenicity of certain chemical substances remains limited within factories or to the one voluntarily smoking tobacco, the difficulty in demonstrating a statistical significance of the data can sometimes be adduced as sufficient evidence for harmlessness. Thus, although epidemiological evidence suggests that even average or relatively low pollution levels can have adverse health effects, environmental concentrations of pollutants directly related to energy production and consumption, activities of some industries, and massive use of some industrial 
products, like cars, continue to increase. Advances in scientific knowledge on the mechanisms underlying the multifactorial and multistage process of carcinogenesis are highly beneficial for the improvement of diagnostic and therapeutic tools, as well as for the refinement of primary prevention initiatives. It is therefore desirable that primary prevention measures are taken after considering all the available facts and information. This brings up the need for institutional consultations on tobacco policy and measures for the protection of workers and the general population at risk from asbestos, or the development of transport policies that reduce environmental contamination of urban areas. We must be aware that we cannot wait to get all the information and data (which the currently available technology is unable to provide anyway) for the adoption of preventive measures. It must be emphasized that even if only weak or inconclusive evidence is available for the carcinogenicity of a substance, this should be treated as sufficient reason to take preventive or precautionary action to alleviate long-term, irreversible effects on public health.

Vaccination directly targets the causative agents of precancerous lesions and cervical cancer. Thus, intense research has been conducted to produce prophylactic vaccines against specific HPV strains [132]. Prophylactic strategies concentrate on eliciting successful humoral immune responses that might protect against HPV infection in the future. Induction of capsid-specific neutralizing antibodies might help to prevent HPV infection. Virus-like particles (VLPs) have been synthesized using recombinant techniques to express the L1 main capsid protein to induce neutralizing antibody responses, and remarkable immune-prophylactic results have been demonstrated in humans and other animals [132]. HPV VLP vaccines induce high titers of conformationally-dependent, typespecific HPV-neutralizing antibodies. Overcoming type-specificity issues with responses to VLP vaccines is a potentially important field of current HPV vaccine research, with a focus on inducing broad and cross-protective neutralizing responses. Techniques to enhance cellular immunity by improving viral antigen recognition are being investigated as a treatment for existing HPV infections. Thus, the current clinical trials on cervical cancer have focused on the oncogenic proteins E6 and E7 of HPV-16 and -HPV-18. The viral oncogenes E6 and E7 are present in HPV-related cancers and are potential targets for HPV therapeutic vaccines [133]. In clinical trials of therapeutic vaccines with various preclinical animal papillomavirus models, several approaches are being evaluated for efficacy. To increase cell-mediated immunity to papillomavirus proteins found in HPV infections and cancers, researchers have used genetic vaccines [134], recombinant virus vaccines [135], dendritic cell-based strategies [136], immunomodulatory strategies [137], and various combination strategies [138]. The effectiveness of HPV VLP vaccines for prevention is undeniable. The current vaccine clinical trials, on the other hand, have been less successful in disease clearance. Nonetheless, several combination approaches have shown substantial therapeutic improvement in preclinical papillomavirus models and are being tested in patient populations to determine which one is the most effective. The successful development of HPV-specific vaccines could provide an appealing and cost-effective alternative to current cervical cancer screening and treatment programs [139, 140]. They are nearly $100 \%$ safe, only mildly reactogenic, and are among the best vaccines ever created. The disadvantages of anti-HPV vaccines include the fact that the benefits can take 20 to 30 years to manifest, and that they do not provide immunity against all oncogenic HPVs. Hence, it is important to continue organized cytological screening, which will remain the primary tool for cervical cancer prevention for many decades. Other vaccines, besides VLP-based vaccines, are likely to be in development, including those that might either be able to inhibit an already progressing infection 
or be used in cervical cancer immunotherapy [141]. Vaccination of girls aged 8 to 14 years is the most effective strategy. Other methods to consider include vaccinating teenage and non-sexually active women, as well as sexually active women. Primary prevention techniques should be developed in tandem with secondary prevention by redesigning screening systems. The cooperation of public health agencies, the collaboration of health workers from various areas, and enhanced public awareness are needed for the effective implementation of vaccination programs [142]. Other immunotherapeutic options against HPV-associated diseases, such as therapeutic vaccines, are constantly being investigated. By modulating dendritic cells and cytotoxic $T$ lymphocytes, therapeutic HPV vaccines improve cell-mediated immunity against HPV E6 and E7 antigens [143]. Immune checkpoint inhibitors have only recently been approved for use in the treatment of HPVrelated cervical cancer [144-147]. In Italy, since 2007, public vaccination against HPV is conducted for all girls who are 12 years old, as the vaccine neutralizes the virus when it is present only in the vagina. The site-specific activity of the vaccine makes it ineffective in women who have already been infected [148]. Vaccines have not replaced screening, but this needs to be changed. Vaccines can more easily reach the sections of the population that are reluctant to participate and trust screening programs, and this is important because most cervical cancers occur in women who do not undergo Pap smears [149-151].

\subsubsection{Secondary Prevention}

Secondary prevention includes Pap smears, liquid-based or thin layer cytology (LBC), and HPV detection (HPV tests). The objectives of secondary prevention require clinical-therapeutic measures aimed at:

1. Diagnosis of the disease in its early stages; and

2. The greater effectiveness of therapeutic interventions

One of the most promising approaches to reduce the emergence of cancer is early detection. Early detection also plays an important role in the treatment of cervical and breast cancer, and it is expected to play an even bigger role in the treatment of colorectal, prostate, and lung cancer in the future. The introduction of new molecular technologies that can detect cellular changes at the genome or proteome level has recently re-energized early detection science [152].

The term "oncological screening" refers to the overall efforts made to identify tumors at an early stage. These studies are conducted on subjects who do not have any signs or symptoms of a neoplasm. It is possible to include the entire population over a certain age, only one sex, or only subjects with a high risk of developing cancer due to genetic, professional, or discretionary reasons. When risk factors that can be prevented are identified, screening programs should be combined with campaigns aimed at cancer prevention by appropriate measures. The objective of cancer screening, on the other hand, cannot be limited to the detection of a larger number of tumors. Screening is worthwhile only if it decreases overall mortality or, at least, mortality for a specific tumor. Screening can also allow the diagnosis of a disease when there is a chance of recovery, which is more difficult when the disease is detected, i.e., when signs or symptoms appear. This is why not all cancer screening campaigns are equally successful. Every year, about 150,000 people die in Italy due to cancer [153]. If detected early enough, some of these tumors can be treated successfully. Noninvasive procedures can be used to detect cervical cancer. Pap test is a screening method that is used globally and can be performed on an entire healthy population that might be at risk of 
contracting cancer. Screening programs have been started hoping to save many of the approximately 270,000 new cancer cases registered annually. Screening is performed according to the national guidelines to ensure quality; these protocols are subject to change over time to incorporate new information or to correct any system errors. The following is a simplified procedure for a potential cancer screening route:

1. Following the selection of the target demographic, for example, all women aged 25 to 64 years (in the case of cervical cancer monitoring), all the individuals are sent an invitation letter with the date and time of the appointment, which is scheduled according to the hospital's acceptance capability.

2. The patient is examined, which may or may not include a Pap smear, depending on the person and the type of cancer to be monitored.

3. Once the test results are available, they are communicated to the individual concerned, who are notified by mail and recalled for a second test at a later date. In case of positive results, the patient is contacted over the telephone and suggested to undergo additional examinations; the patient is said to be in "phase two" of their treatment.

4. In phase two, which is only applicable for a limited percentage of those who were tested initially (usually less than 3-5\%), detailed tests are performed, which, depending on the person and the type of cancer, might include cytological and colposcopic examinations, removal of a fragment of tissue (biopsy) and subsequent histological analysis, and additional tests such as ultrasound, radiography, computerized tomography (CT), MRI, and positron emission tomography (PET), among other tests. In case of negative results, the patient is contacted for new control tests at a later date; in case of positive results, the patient is recommended an oncological therapeutic strategy and/or surgery to treat the diagnosed tumor.

5. Once the treatment is over, the patient enters a follow-up regimen in which the tumor is tracked over time to determine whether it has been removed successfully or is still growing.

Substantial reductions in the incidence and mortality from cervical cancer have been observed after the introduction of prevention campaigns with the implementation of cervical screening programs through Pap tests and, in particular, following the introduction of organized programs, which guarantee a high level of screening coverage, as well as, the quality and continuity of diagnostic-therapeutic procedures. It is estimated that Pap smear screening every 3-5 years provides $80 \%$ protection from cancer onset [154]. The rationale for introducing population screening for cervical cancer is based on the possibility of identifying the disease in the asymptomatic phase when the probability that the disease is in the preinvasive or initial invasive phase is higher. Pap smear is not aimed at identifying other infections of the female genital system, although, in some circumstances, it might reveal genital infections and other cancers of the female genital tract. The Pap test not only identifies very early tumor lesions but also identifies the preneoplastic lesions. Therefore, screening can not only reduce the mortality from carcinoma (favoring the diagnosis in a phase in which treatment can be effective) but can also reduce the incidence of invasive neoplasm through the treatment of preneoplastic forms. The effectiveness of screening by Pap smear is reflected in the temporal variations in mortality from cervical cancer across different geographical areas. Evidence from active interventions in (more or less) large populations and non-randomized studies have shown a significant reduction in the incidence of invasive cancers in women subjected to the Pap test [155]. The extent of the reduction in the mortality from cervical cancer in a certain geographical area is related to the percentage of the 
population that underwent screening, the age group included in the program, and the participation by the invited population. The analysis of the different ranges of re-screening adopted and different age groups included in the programs at a population scale provides information and data that can be used to calculate the theoretical effectiveness of the different screening policies.

Outside organized cytology screening programs, the Pap test is called "spontaneous screening". It has been estimated that, on average, it counts about 3.5-4.0 million Pap tests every year. This implies that annually one out of every three or four women, aged between 25 and 64 years, performs the test. Therefore, the number of tests conducted should almost be sufficient to guarantee coverage in the age group subjected to screening, with re-screening every three years. However, the actual proportion of women who periodically undergo the Pap test is much lesser, and often this group performs frequent testing (tests performed annually or even more frequently). On the other hand, a large part of the female population has never taken the test or perform it irregularly. This segment of the population that has not undergone the Pap test is at a higher risk of having cervical cancer; these women should be given priority in active screening programs. In Italy, the spread of spontaneous Pap tests since the 1960s and the initiation of organized screening programs two decades ago were the main factors in reducing the incidence and mortality from neoplasm. Regional screening programs currently cover $84 \%$ of the female population aged 25-64 years (2019 data) [156]. It is recommended to conduct a screening program for Italians aged between 25 and 64 years covering $85 \%$ of the female population, with a Pap smear done every three years through an organized screening program. Spontaneous tests that are not performed according to these norms should not be recommended. Spontaneous tests must, in any case, not exceed $10 \%$ of the ones performed by organized programs and they must be adequately motivated. Cervical cancer screening is undoubtedly the most effective cancer screening procedure. Surprisingly, its efficacy is one of the most compelling arguments against HPV vaccination in countries where Pap test screening program is well-organized. Pap test is the first screening test for cervical cancer, more commonly known as the cervicovaginal smear. It has been widely used for over 60 years and kept virtually unchanged to date. Cervical cancer screening guidelines for sexually active women from 25 to 64 years of age mention that individuals should perform the Pap test by inspecting the material taken from the cervix with a small spatula and brush the sample under a microscope after staining it with a clear "thin prep" stain. The test should be repeated every three years. Women who have been vaccinated against HPV must continue to be screened with Pap tests. The reasons for the success of this method are:

1. The discovery in $\mathbf{1 9 7 5}$ that some cellular morphological changes (koilocytosis) were linked to the presence of HPV infection.

2. The consensus obtained in 1988 and 2001 on a reporting system capable of making cytological interpretation more homogeneous and reproducible and establishing a unique diagnostic study design.

Currently, the most widely used system for reporting cervical cytology is the 2001 Bethesda system (Table 3) [157, 158]. 
Table 3 The 2001 Bethesda system for reporting cervical cytology.

Specimen adequacy:

- satisfactory for evaluation:

- presence or absence of endocervical or transformation zone components or other quality indicators such as partially obscuring blood or inflammation;

- unsatisfactory for evaluation (specify the reason):

- specimen rejected or not processed (specify the reason);

- a specimen processed and examined, but unsatisfactory for evaluation of epithelial abnormalities (specify the reason);

General categorization (optional):

- negative for intraepithelial lesion or malignancy;

- epithelial cell abnormality;

- other;

Interpretation/result:

- negative for intraepithelial lesion or malignancy;

- organisms:

- Trichomonas vaginalis;

- fungal organisms morphologically consistent with Candida species;

- the shift in flora suggesting bacterial vaginosis;

- bacteria morphologically consistent with Actinomyces species;

- cellular changes consistent with Herpes Simplex Virus (HSV);

- other non-neoplastic findings (optional to report):

- reactive cellular changes associated with:

- inflammation (includes typical repair);

- radiation;

- contraceptive intrauterine device (IUD);

- post-hysterectomy glandular cell status;

- atrophy;

- epithelial cell abnormalities:

- squamous cells:

- atypical squamous cells (ASC):

- ASC of undetermined significance (ASC-US);

- ASC, cannot exclude high-grade squamous intraepithelial lesion (ASC-H);

- low-grade squamous intraepithelial lesion (L-SIL):

- encompassing: Human Papillomavirus (HPV), mild dysplasia, and cervical intraepithelial neoplasia (CIN) 1;

- high-grade SIL (H-SIL):

- encompassing: moderate and severe dysplasia, carcinoma in situ (CIS), CIN 2, and CIN 3;

- squamous cell carcinoma (SCC);

- glandular cells:

- atypical glandular cells (AGC):

- specify endocervical, endometrial, or AGC not otherwise specified (NOS); 
- AGC, favor neoplastic:

- specify endocervical or NOS;

- endocervical adenocarcinoma in situ (AIS);

- adenocarcinoma;

- other (not comprehensive list):

- endometrial cells of a woman 40 years or older;

Automated review and ancillary testing (include if applicable);

Educational notes and suggestions (optional).

While some screening systems (e.g., Pap smears) have been successful in reducing cancer-related mortality, no screening program is flawless. Screening procedures are applied to a significant portion of the population that appears to be stable. Limits for some diseases, in particular, can be quite evident to preclude the implementation of a systematic screening program. There are two types of potential drawbacks of formal screenings, organizational and medical. The capacity of a program to attract the entire target population is limited by the organizational form. A screening program, no matter how well-organized, is hardly able to cover more than $70-80 \%$ of the target population, and the outcomes of existing programs are often even lower. The ability to reduce total mortality or individual mortality using a specific screening campaign represents the limit of the medical form [159-160].

Liquid-based cytology (LBC) was introduced in the mid-90s. By this method, one can achieve a high-quality monolayer preparation (thin layer) without interference, i.e., a preparation free from blood and mucus and from layers of superimposed material with few inflammatory elements that rarely hinder a correct interpretation. Thus, it is more sensitive than the conventional Pap test, has a lower percentage of inadequate preparations, and has a greater interpretative reproducibility between operators. Several different LBC techniques have been used, among which, ThinPrep ${ }^{\circledR}$ and Surepath ${ }^{\circledR}$ have received FDA approval and are widely used methods. The test is very simple and requires collecting a sample of cervical cells with a cytobrush in the same way as in the Pap test; the instrument is then shaken in a jar containing a preservative. Slide preparations are automatic, using an instrument where the suspended cells are collected by aspiration or sedimentation on the surface of a membrane and then transferred to the slide. LBC also has the advantage of allowing the application of molecular methods for HPV and the detection of progression markers with immunocytochemical techniques on the same sample. Regarding this, while selecting the LBC system, attention must be paid to the characteristics of the preservative liquid, which must be able to maintain DNA stability at room temperature for a minimum of 30 days and allow evaluation of ribonucleic acid (RNA). Automated reading systems of cervicovaginal smears prepared in the traditional way or thin layers have also been introduced. Some systems make an automatic selection of a quote of smears that can be considered as negative without further review by cytologists, others select the most "suspicious" fields of each smear, and some combine both approaches. Such systems have demonstrated a sensitivity comparable to that of traditional reading, and some are approved by the FDA for primary screening. It is recommended to classify cytological preparations according to comparable accredited systems and histological ones based on the classification recommended by the World Health Organization (WHO), using the Systematized Nomenclature of Human and Veterinary Medicine (SNOMED) code. It is also appropriate to officially adopt conversion tables between different classification systems. Finally, it is recommended to adjust the medical 
contents of the report as per the directives of the European Economic Community (EEC). Reporting, registering, and archiving of preparations must be automated, using software and classifications compatible with the municipal registry data and health registers.

The current specificity of the Pap test in predicting cancer and its progressive premalignant lesions is minimal. HPV infections can lead to cervical cancer by causing genetic instability, hyperproliferation, and immortalization of the mucosa. Several molecular markers linked to this neoplastic mechanism are informative [161]. Quantitative chromosomal and DNA aneuploidy analysis is a useful method for detecting H-SIL progression [162]. For accurate and repeatable measurements, a high level of standardization (material handling, calibration and quality control, measurement, and interpretation of results) is needed [162]. Advances in diagnostic techniques, in particular, the development of easy-to-use molecular genetic tests, are replacing the use of the consolidated Pap test as a screening tool. HPV testing, using HPV DNA from exfoliated cervical cells, has been proposed based on the evidence of the role of "high-risk" types of HPV (especially HPV$16,18,31,33,45,51,52$, and 56) as the etiological agent of cervical cancer [163]. A significant increase in the validity of the available techniques allowed to demonstrate the presence of "highrisk" HPV in a high percentage of both invasive cancers and H-SIL, while the prevalence was low in the healthy population and moderate in L-SIL [164]. The HPV test is always performed on a small sample of cells taken from the cervix, as in the Pap test. However, it is not a morphological exam but a molecular biology exam that allows detecting the presence of HPV by identifying its DNA or messenger RNA (mRNA). The results of numerous experimental studies have demonstrated a greater sensitivity of the HPV test compared to the traditional Pap test, at the expense of a lower specificity, due to two main factors:

1. The HPV test is based on the search for 12-14 types of viruses that have a greater oncogenic potential [165]; and

2. The HPV test does not discriminate between transient infections and persistent and productive infections [165].

The most promising uses appear to be:

1. As a secondary selection method for individuals to be recommended colposcopy, among those with low-grade cytology (L-SIL) or borderline cytology (ASC-US). Management of these cases is difficult because a non-negligible proportion of the subjects, whose cytology is classified as lowgrade or borderline, actually present high-grade histological alterations (CIN 2-3). Several studies have consistently indicated the ability of HPV testing to detect a high percentage of these individuals [166-168]; and

2. HPV typing, by hybrid capture (HC) II or polymerase chain reaction (PCR), in cytologically negative subjects, for redefining screening intervals.

The most widely used molecular tests are based on the search for HPV viral sequences and genotyping using molecular biology techniques, such as direct hybridization, qualitative PCR, and viral nucleotide sequencing. Direct hybridization or HC is a non-radioactive, accurate, and reproducible method with high sensitivity and is the only method approved by the FDA. It is a liquidphase molecular hybridization test comprising microplate capture of cervical cleavage cells. The test is capable of determining very low concentrations of DNA and can be used to determine low-risk HPVs (HPV-6, 11, 42, 43, and 44) and high-and intermediate-risk HPVs (HPV-16, 18, 31, 33, 35, 39, $45,51,52,56$, and 58). However, it cannot identify a single viral type nor the exact viral load, which is calculated semi-quantitatively using a chemiluminescence intensity gradient. The method consists 
of the denaturation of single-stranded DNA, which is hybridized in solution with mixed RNA probes, where one probe highlights low-risk types and another highlights high-risk oncogenic viruses. Each reaction mixture containing the formed RNA/DNA hybrids is transferred to a test tube with polyclonal antibodies directed against the RNA/DNA hybrids adhering to the test tube walls. The bound hybrids are then reacted with an antibody, directed against the RNA/DNA hybrids, conjugated with alkaline phosphatase. Any unbound material is removed by washing, and then a chemiluminescent substrate is added, which binds to the alkaline phosphatase. The light produced by the reaction is measured using a luminometer in relative light units (RLU).

Real-time PCR is an application of classical PCR and provides more precise quantitative information on the concentrations of the amplified DNA. Any nucleic acid sequence present in a sample can be amplified by a cyclic process to generate many identical copies, which can subsequently be analyzed. PCR is characterized by a series of cycles at different temperatures that allow denaturation of the target DNA molecules, hybridization of specific primers, and elongation of the chain by the Thermus aquaticus (Taq) polymerase. Each cycle consists of three stages and can be repeated 20-40 times. The easiest way to identify a PCR product is to continuously monitor the progress of the reaction without having to stop the reaction to view it on a gel. Real-time implies that data collection and analysis occur simultaneously with the reaction. Nucleotide sequencing allows the nucleotide sequence of a nucleic acid molecule to be read in the correct order and thus, reveals the type of HPV present. The most commonly used technique in recent years is pyrosequencing [169-172]. This technique allows DNA sequencing by synthesis. The detection system depends on the pyrophosphate released when a nucleotide is added to the DNA strand; the signal is quantitatively related to the number of bases added and detected in a pyrogram. The genome of the different types of HPV viruses is different, and therefore, generates different types of pyrograms, thus identifying the virus accurately. However, the method is not easy to use, it cannot be automated, and it is very expensive [173, 174].

Modern imaging methods aid in the detection of small tumors in the parts of the body that are difficult to reach. Thus, minimally invasive procedures are used, including fine needle aspiration (FNA), to sample cellular material. Tumor cells should be identified for prognostically important features for optimal care. FNA and exfoliative cytology are used to examine primary and metastatic neoplasms, as well as individual disseminated cells in solid tumors. Immunochemistry and PCRbased molecular studies help in the identification and genotyping of tumor cells. Immunostaining, in particular, necessitates laboratory procedures tailored to cytology samples. Cell image analysis, particularly for DNA ploidy and chromosomal fluorescence in situ hybridization (FISH) of interphase cells, might add predictive value to morphological data. Immunochemistry and PCR of cytological materials are used to investigate prognostic tumor cell markers. For dissociated solid tumor cells, cytology must promote translational research and validate the effects of molecular cytogenetics, such as comparative genomic hybridization (CGH) and complementary DNA (cDNA) microarray techniques. Newly discovered genetic variations could be assessed for their functional significance and linked to structural changes in tumor cells [175]. The high sensitivity of array-based technologies, as well as the identification of panels of molecular fingerprints that are unique to each disease, is expected to aid pathologists in evaluating cytological samples and tissue biopsies in conjunction with morphological parameters in the future [176]. This method could usher a new era in diagnosis and patient care, where each patient would receive individualized treatment based on the 
molecular characteristics of the disease, which could be extracted from a small sample of tissue [177].

As we have seen, Pap smear is hampered by weak inter-and intra-observer agreement due to arbitrary test requirements. More reproducible assays might enhance the quality of the current screening process and prevent unnecessary medical intervention and psychological distress among individuals. Evidence indicates that HPV infection alone is insufficient to cause malignant changes and that other host genetic variations play a role in the growth of cervical cancer. Despite the introduction of screening programs for HPV-related cancers, especially cervical cancer, researchers continue to discover viral and host biomarkers that might help to identify individuals with precancer or cancer more efficiently. In both primary screening and triage settings, novel biomarkers that enable monitoring of these critical molecular events in histological or cytological specimens could improve the identification of lesions that have a high risk of progression. Biomarker discovery and detection of molecular targets linked to carcinogenesis have entered a new age owing to advances in molecular biology and high throughput gene expression profiling technologies. These breakthroughs have strengthened our understanding of carcinogenesis and will make screening, early detection, management, and tailored targeted therapy more accessible. Several novel genes that are differentially expressed in cervical cancer, including some genes involved in cell cycle control, have been identified using high-density microarrays to determine gene expression profiles in cervical cancer; p16INK4a, MCM 3, MCM 5, CDC6, Geminin, Cyclins A-D, topoisomerase 2-alpha (TOPO2), cadmium-containing carbonic anhydrase 1 (CDCA1), and baculoviral inhibitor of apoptosis repeat-containing 5 (BIRC5) are among them. Real-time PCR has been used to confirm mRNA expression, and immunohistochemistry has been used to confirm protein expression [178, 179]. To induce and sustain cervical carcinogenesis, epithelial stem cells must produce two viral oncogenes, E6 and E7, which results in substantial overexpression of the cellular protein 16-cyclin-dependent kinase 4 inhibitor (p16INK4a). Since this protein is not expressed in regular cervical squamous epithelia, searching for p16INK4a overexpressing cells allows one to more precisely identify dysplastic lesions and eliminates inter-observer variability in traditional cytological or histological tests. Extensive recombination of the viral and cellular genomes is correlated with the progression of preneoplastic lesions to invasive cancers, which can be tracked by the detection (amplification) of HPV oncogene transcripts (APOT assay) derived from combined viral genome copies. Detection of integrated type oncogene transcripts indicates advanced dysplasia or invasive cancers and thus, serves as a marker for the progression of cervical lesions [180]. Nonrandom host somatic chromosomal variations are commonly seen in HPV-related cancers but at varying rates and might have functional implications. In the case of the 3q26 mutation, there is strong preliminary evidence that this genomic change can be used as a biomarker for cervical cancer disease progression [181]. The FISH-based HPV-associated cancer test detects genomic imbalance at four loci (3q26, 5p15, 20q13, and centromere 7) on a cell-by-cell basis in cytology specimens in a single hybridization [182]. The FISH-based HPV-associated cancer test, when used as a secondary screening assay, might aid in the identification of clinically significant HPV-associated diseases and help in patient management [183].

Since the discovery of the HPV oncogenes E6 and E7, which result in cancer cell senescence, cervical cancer has been an appealing model to test gene-specific therapies. Antisense oligonucleotides, ribozymes, and, more recently, small interfering RNA (siRNA)-based therapies have all been studied as oligonucleotide-based therapies. Cancers, genetic disorders, and viral 
infections have all been subjected to siRNA-based therapies, which have several advantages over antisense and ribozyme technologies. In vitro testing of siRNA against cervical cancer has yielded promising results, but the same issues that hampered the clinical development of ribozymes and antisense oligonucleotides are now posing problems for the siRNA field: target selection, specificity, and delivery. If these problems are resolved, a variety of new and effective cervical cancer treatments could be available [184-194].

\section{Conclusions}

Genetic screening, and its various aspects, has proven to be a valid medical process, as it can prevent the emergence of potentially serious genetic diseases and/or can help prevent the birth of newborns with fatal diseases. In the next few years, it is expected that genetic screening will be extended to primary and secondary prevention of complex diseases and the identification of the efficacy and possible side effects of drugs, thus allowing the formulation of personalized medicine. For the medical procedure to be successful and not lead to negative effects, it must be preceded and followed by a thorough genetic consultation that illustrates its advantages and disadvantages [195]. The latest guidelines of the American Cancer Society (ACS) for early detection of cancer in asymptomatic individuals, which have been updated almost 40 times, provide screening recommendations for breast, colorectal, prostate, and cervical cancers, among other cancers, based on patient age, experience, environmental and/or occupational exposures, and other factors. The differences between the public health guidelines for screening and the individual decisions about early detection tests are an important matter for both the general public and health care providers. While newer technologies, such as genetic and molecular markers of risk and disease, are likely to supplant current screening protocols, a greater use of the technologies available now can strengthen the efforts to develop a coordinated and systematic approach to early cancer detection [196].

In gynecological oncology, molecular pathology currently has a limited role in enhancing patient outcomes. Molecular research, on the other hand, is shedding light on the epidemiology, pathogenesis, and development of female genital cancers. Prediction of poor outcome in low-risk cases, more precise staging of multifocal tumors, detection of new precursor lesions, and prediction of response to various therapeutic regimens should all be part of the future roles. Any patient with a malignant tumor will benefit from gene therapy in the future. However, the most important task of molecular pathology will be in the screening and triage of putative cervical cancer precursors, as well as the prophylaxis of these lesions with HPV vaccines [197]. Cervical cancer is a complex disease that has sparked research in many areas related to its basic diagnostic and clinical aspects due to its connection to HPV [198-200]. This association is complicated not only because of the fundamental nature of the relationship between virus and cancer but also because of how it translates to pathological diagnosis and clinical management [201]. Studies on the association between HPV infection and cervical epithelial abnormalities, the molecular epidemiology of HPV infection, and the possible use of HPV testing as a screening technique, or a method for treating women with Pap smear abnormalities, are all offshoots of the virus-pathology relationship [202]. The cervical transformation zone is another important factor in the pathogenesis of cervical neoplasia. The broad range of invasive and noninvasive lesion phenotypes linked to HPV infection in this area suggests that not only the virus but also the unique target epithelial cells of the host in the 
transformation zone play a role in the growth of cervical neoplasia. Determining the subtypes of epithelial cells in the transformation region and their phenotypic response to infection would help researchers better understand the relationship of the virus with the host epithelium. The complexity of the molecular interactions contributing to the multiplicity of tumor phenotypes associated with HPV infection in the uterine cervix will be clarified, if not resolved, by new technologies such as expression arrays [203-215].

\section{Author Contributions}

The authors contributed equally to this work.

\section{Competing Interests}

The authors have declared that no competing interests exist.

\section{References}

1. Burke W, Coughlin SS, Lee NC, Weed DL, Khoury MJ. Application of population screening principles to genetic screening for adult-onset conditions. Genet Test. 2001; 5: 201-211.

2. Leung $Y$, DePetrillo AD. Etiology, epidemiology, risk and prognostic factors, screening, and imaging of gynecologic cancers. Curr Opin Oncol. 1993; 5: 869-876.

3. Lathrop AEC, Loeb $L$. The influence of pregnancies on the incidence of cancer in mice. Proc Soc Exp Biol Med. 1913; 11: 38-40.

4. Berenblum I. The modifying influence of dichloroethyl sulphide on the induction of tumours in mice by tar. J Pathol Bacteriol. 1929; SS: 425-434.

5. Tannenbaum A. The initiation and growth of tumors. Introduction. 1. Effect of underfeeding. Am J Cancer. 1940; 38: 335-350.

6. Tannenbaum A. The genesis and growth of tumors. II. Effects of caloric restriction per se. Cancer Res. 1943; 3: 749-756.

7. Visscher $M B$, Ball ZB, Barnes RH, Sivertsen I. The influence of caloric restriction upon the incidence of spontaneous mammary carcinoma in mice. Surgery. 1942; 11: 48-55.

8. Slaughter DP, Southwick HW, Smejkal W. "Field cancerization" in oral stratified squamous epithelium. Clinical implications of multicentric origin. Cancer. 1953; 6: 963-968.

9. Strong MS, Incze J, Vaughan CW. Field cancerization in the aerodigestive tract - Its etiology, manifestation, and significance. J Otolaryngol. 1984; 13: 1-6.

10. Kristal AR, Lippman SM. Nutritional prevention of cancer: New directions for an increasingly complex challenge. J Natl Cancer Inst. 2009; 101: 363-365.

11. Gann PH. Randomized trials of antioxidant supplementation for cancer prevention: First bias, now chance-next, cause. JAMA. 2009; 301: 102-103.

12. Morales A, Eidinger D, Bruce AW. Intracavitary Bacillus Calmette-Guerin in the treatment of superficial bladder tumors. J Urol. 1976; 116: 180-183.

13. Sporn MB. Combination chemoprevention of cancer. Nature. 1980; 287: 107-108.

14. Blaser MJ. Understanding microbe-induced cancers. Cancer Prev Res. 2008; 1: 15-20.

15. Papanicolaou GN. New cancer diagnosis. Proceedings of the Third Race Betterment Conference; 1928 January 2-6; Battle Creek, MI, US. pp.528-534. 
16. Wolff WI. Colonoscopy: History and development. Am J Gastroenterol. 1989; 84: 1017-1025.

17. Lynch HT, Krush AJ. Cancer family “G” revisited: 1895-1970. Cancer. 1971; 27: 1505-1511.

18. Lynch HT, Harris RE, Organ Jr CH, Guirgis HA, Lynch PM, Lynch JF, et al. The surgeon, genetics, and cancer control: The Cancer Family Syndrome. Ann Surg. 1977; 185: 435-440.

19. Lynch HT, Albano WA, Lynch JF, Lynch PM, Campbell A. Surveillance and management of patients at high genetic risk for ovarian carcinoma. Obstet Gynecol. 1982; 59: 589-596.

20. Lynch HT, Harris RE, Organ Jr CH, Lynch JF. Management of familial breast cancer. I. Biostatistical-genetic aspects and their limitations as derived from a familial breast cancer resource. Arch Surg. 1978; 113: 1053-1058.

21. Lynch HT, Organ Jr CH, Harris RE, Guirgis HA, Lynch PM, Lynch JF. Familial cancer: Implications for surgical management of high-risk patients. Surgery. 1978; 83: 104-113.

22. Lippman SM, Hawk ET. Cancer prevention: From 1727 to milestones of the past 100 years. Cancer Res. 2009; 69: 5269-5284.

23. Tierney LM, NcPhee SJ, Papadakis MA. Current medical diagnosis \& treatment. New York: Appleton \& Lange; 1997.

24. Ustun C, Ceber E. Ethical issues for cancer screening. Asian Pac J Cancer Prev. 2003; 4: 373-376.

25. Ustun C, Ceber E. Ethical issues for cancer screenings. Five countries - four types of cancer. Prev Med. 2004; 39: 223-229.

26. Morley TJ, Han L, Castro VM, Morra J, Perlis RH, Cox NJ, et al. Phenotypic signatures in clinical data enable systematic identification of patients for genetic testing. Nat Med. 2021; 27: 10971104.

27. Conti A, Delbon P, Sirignano A. Informed consent when taking genetic decisions. Med Law. 2004; 23: 337-353.

28. Chitty LS. A new decade, fond farewells and a new era for Prenatal Diagnosis. Prenat Diagn. 2021; 41: 3-4.

29. Milunsky A. Genetic disorders and the fetus: Diagnosis, prevention and treatment. $3^{\text {rd }}$ ed. Baltimore, Maryland: John Hopkins University Press; 1992.

30. Cao A, Rosatelli MC. Screening and prenatal diagnosis of the haemoglobinopathies. Baillieres Clin Haematol. 1993; 6: 263-286.

31. Wald NJ, Watt HC, Hackshaw AK. Integrated screen for Down's syndrome on the basis of tests performed during the first and second trimesters. N Engl J Med. 1999; 341: 461-467.

32. Cao A, Rosatelli MC, Eckman JR. Prenatal diagnosis and screening for thalassemia and sickle cell disease. In: Disorders of hemogoblin: Genetic, pathophysiology and clinical management. Cambridge: Cambridge University Press; 2001.

33. Wald NJ, Rodeck C, Hackshaw AK, Walters J, Chitty L, Mackinson AM. First and second trimester antenatal screening for Down's syndrome: The results of the Serum, Urine and Ultrasound Screening Study (SURUSS). Health Technol Assess. 2003; 7: 1-77.

34. Malone FD, Canick JA, Ball RH, Nyberg DA, Comstock CH, Bukowski R, et al. First-trimester or second-trimester screening, or both, for Down's syndrome. N Engl J Med. 2005; 353: 2001-2011.

35. Sekizawa A, Purwosunu Y, Matsuoka R, Koide K, Okazaki S, Farina A, et al. Recent advances in non-invasive prenatal DNA diagnosis through analysis of maternal blood. J Obstet Gynaecol Res. 2007; 33: 747-764.

36. Zimmer KP. Newborn screening: Still room for improvement. Dtsch Arztebl Int. 2021; 118: 99100. 
37. McCabe LL, Therrell BL, McCabe ER. Newborn screening: Rationale for a comprehensive, fully integrated public health system. Mol Genet Metab. 2002: 77: 267-273.

38. Wilcken B, Wiley V, Hammond J, Carpenter K. Screening newborns for inborn errors of metabolism by tandem mass spectrometry. N Engl J Med. 2003; 348: 2304-2312.

39. Botkin JR. Research for newborn screening: Developing a national framework. Pediatrics. 2005; 116: 862-871.

40. Natowicz M. Newborn screening - setting evidence-based policy for protection. N Engl J Med. 2005; 353: 867-870.

41. Stepien KM, Kieć-Wilk B, Lampe C, Tangeraas T, Cefalo G, Belmatoug N, et al. Challenges in transition from childhood to adulthood care in rare metabolic diseases: Results from the first multi-center European survey. Front Med. 2021; 8: 652358.

42. Kaback M, Lim-Steele J, Dabholkar D, Brown D, Levy N, Zeiger K. Tay-Sachs disease - carrier screening, prenatal diagnosis, and the molecular era. An international perspective, 1970 to 1993. JAMA. 1993; 270: 2307-2315.

43. Grody WW, Cutting GR, Klinger KW, Richards CS, Watson MS, Desnick RJ. Laboratory standards and guidelines for population-based cystic fibrosis carrier screening. Genet Med. 2001; 3: 149154.

44. Watson MS, Cutting GR, Desnick RJ, Driscoll DA, Klinger K, Mennuti M, et al. Cystic fibrosis population carrier screening: 2004 revision of American College of Medical Genetics mutation panel. Genet Med. 2004; 6: 387-391.

45. American Academy of Pediatrics, committee on genetics: Issues in newborn screening. Pediatrics. 1992; 89: 345-349.

46. Borry P, Fryns JP, Schotsmans P, Dierickx K. Carrier testing in minors: A systematic review of guidelines and position papers. Eur J Hum Genet. 2006; 14: 133-138.

47. Divella R, DE Palma G, Tufaro A, Pelagio G, Gadaleta-Caldarola G, Bringiotti R, et al. Diet, probiotics and physical activity: The right allies for a healthy microbiota. Anticancer Res. 2021; 41: 2759-2772.

48. Khoury MJ, McCabe LL, McCabe ER. Population screening in the age of genomic medicine. N Engl J Med. 2003; 348: 50-58.

49. French DP, Howell A, Evans DG. Psychosocial issues of a population approach to high genetic risk identification: Behavioural, emotional and informed choice issues. Breast. 2018; 37: 148153.

50. Evans WE, Relling MV. Moving toward individualized medicine with pharmacogenomics. Nature. 2004; 429: 464-468.

51. McGinniss MJ, Kaback MM. Heterozygote testing and carrier screening. In: Emery and Rimoin's principles and practice of medical genetics. 4th Ed. London: Churchill Livingston; 2002.

52. Hussein N, Weng SF, Kai J, Kleijnen J, Qureshi N. Preconception risk assessment for thalassaemia, sickle cell disease, cystic fibrosis and Tay-Sachs disease. Cochrane Database Syst Rev. 2018; 3: CD010849.

53. Ahmad AS, Ormiston-Smith N, Sasieni PD. Trends in the lifetime risk of developing cancer in Great Britain: Comparison of risk for those born from 1930 to 1960. Br J Cancer. 2015; 112: 943947. 
54. Kashyap D, Garg VK, Sandberg EN, Goel N, Bishayee A. Oncogenic and tumor suppressive components of the cell cycle in breast cancer progression and prognosis. Pharmaceutics. 2021; 13: 569.

55. Sekine M, Enomoto T. Precision medicine for hereditary tumors in gynecologic malignancies. J Obstet Gynaecol Res. 2021. doi: 10.1111/jog.14861.

56. Godard B, ten Kate L, Evers-Kiebooms G, Aymé S. Population genetic screening programmes: Principles, techniques, practices, and policies. Eur J Hum Genet. 2003; 11: S49-S87.

57. Petersen GM, Codori AM. Genetic testing for familial cancer. In: The metabolic and molecular bases of inherited disease. 8th Ed. New York: McGraw-Hill; 2001.

58. Cao A, Rosatelli MC. Genetics. Genetic screening. In: Encyclopedia of science and technology. Rome: Treccani; 2007. Available from: https://www.treccani.it/enciclopedia/geneticascreening-genetico (Enciclopedia-della-Scienza-e-della-

Tecnica)/\#: :text=Lo\%20screening\%20genetico\%20consiste\%20nella,screening\%200\%20nei\% 20suoi\%20discendenti.

59. Kuiper RP, Nielsen M, De Voer RM, Hoogerbrugge N. NTHL1 tumor syndrome. In: GeneReviews ${ }^{\circledR}$ [Internet]. Seattle (WA): University of Washington, Seattle; 1993-2020.

60. Chan JK, Chow S, Bhowmik S, Mann A, Kapp DS, Coleman RL. Metastatic gynecologic malignancies: Advances in treatment and management. Clin Exp Metastasis. 2018; 35: 521-533.

61. ASCO/Society of Gynecologic Oncology Special Session. Clinical management of patients with hereditary predisposition to gynecologic (ovarian and endometrial) cancers. Program and abstracts of the $40^{\text {th }}$ Annual Meeting of the American Society of Clinical Oncology; New Orleans, Louisiana; 2004.

62. Lalwani N, Prasad SR, Vikram R, Shanbhogue AK, Huettner PC, Fasih N. Histologic, molecular, and cytogenetic features of ovarian cancers: Implications for diagnosis and treatment. Radiographics. 2011; 31: 625-646.

63. Kuschel B, Köchli OR, Niederacher D, Müller H, Beckmann MW. Hereditary cancer syndromes in gynecology: What the practitioner needs to know! Schweiz Med Wochenschr. 2000; 130: 362-375.

64. Neto N, Cunha TM. Do hereditary syndrome-related gynecologic cancers have any specific features? Insights into Imaging. 2015; 6: 545-552.

65. Rustin GJ. Circulating tumor markers in gynecological tumors. Curr Opin Oncol. 1996; 8: 426431.

66. Murata M. Inflammation and cancer. Environ Health Prev Med. 2018; 23: 1-8.

67. Fang C, Wang SY, Liou YL, Chen MH, Ouyang W, Duan KM. The promising role of PAX1 (aliases: HUP48, OFC2) gene methylation in cancer screening. Mol Genet Genomic Med. 2019; 7: e506.

68. Vaccarella S, Lortet-Tieulent J, Plummer M, Franceschi S, Bray F. Worldwide trends in cervical cancer incidence: Impact of screening against changes in disease risk factors. Eur J Cancer. 2013; 49: 3262-3273.

69. Kim M, Suh DH, Lee KH, Eom KY, Toftdahl NG, Mirza MR, et al. Major clinical research advances in gynecologic cancer in 2018. J Gynecol Oncol. 2019; 30: e18.

70. Torre LA, Bray F, Siegel RL, Ferlay J, Lortet-Tieulent J, Jemal A. Global cancer statistics, 2012. CA Cancer J Clin. 2015; 65: 87-108.

71. Ellenson LH, Wu TC. Focus on endometrial and cervical cancer. Cancer Cell. 2004; 5: 533-538. 
72. Giorgi Rossi P, Chini F, Borgia P, Guasticchi G, Carozzi FM, Confortini M, et al. Human Papilloma Virus (HPV), cervical cancer incidence and screening uptake: Differences among Northern, Central and Southern Italy. Epidemiol Prev. 2012; 36: 108-119.

73. Rotkin ID. A comparison review of key epidemiological studies in cervical cancer related to current searches for transmissible agents. Cancer Res. 1973; 33: 1353-1367.

74. Gissmann L, Boshart M, Dürst M, Ikenberg H, Wagner D, Zur Hausen H. Presence of human papillomavirus in genital tumors. J Invest Dermatol. 1984; 83: S26-S28.

75. Cox JT. Epidemiology of cervical intraepithelial neoplasia: The role of human papillomavirus. Baillieres Clin Obstet Gynaecol. 1995; 9: 1-37.

76. Li Y, Xu C. Human Papillomavirus-Related Cancers. Adv Exp Med Biol. 2017; 1018: 23-34.

77. AIRTUM Working Group. Italian cancer figures, report 2014: Prevalence and cure of cancer in Italy. Epidemiol Prev. 2014; 38: 1-122.

78. Burk RD, Chen Z, Van Doorslaer K. Human papillomaviruses: Genetic basis of carcinogenicity. Public Health Genomics. 2009; 12: 281-290.

79. Stoler MH. Human papillomavirus biology and cervical neoplasia: Implications for diagnostic criteria and testing. Arch Pathol Lab Med. 2003; 127: 935-939.

80. Jayshree RS. The Immune Microenvironment in Human Papilloma Virus-Induced Cervical Lesions - Evidence for Estrogen as an Immunomodulator. Front Cell Infect Microbiol. 2021; 11: 649815.

81. Cason J, Bible J, Mant C. Identification of HPV variants. Methods Mol Med. 2005; 119: 15-25.

82. Martínez-Nava GA, Fernández-Niño JA, Madrid-Marina V, Torres-Poveda K. Cervical cancer genetic susceptibility: A systematic review and meta-analyses of recent evidence. PLoS One. 2016; 11: e0157344.

83. Subramanya D, Grivas PD. HPV and cervical cancer: Updates on an established relationship. Postgrad Med. 2008; 120: 7-13.

84. Horng JT, Hu KC, Wu LC, Huang HD, Lin FM, Huang SL, et al. Identifying the combination of genetic factors that determine susceptibility to cervical cancer. IEEE Trans Inf Technol Biomed. 2004; 8: 59-66.

85. Crosbie EJ, Einstein MH, Franceschi S, Kitchener HC. Human papillomavirus and cervical cancer. Lancet. 2013; 382: 889-899.

86. Harari A, Chen Z, Burk RD. Human papillomavirus genomics: Past, present and future. Curr Probl Dermatol. 2014; 45: 1-18.

87. Mougin C, Dalstein V, Prétet JL, Gay C, Schaal JP, Riethmuller D. Epidemiology of cervical papillomavirus infections. Recent knowledge. Presse Med. 2001; 30: 1017-1023.

88. Steenbergen RD, Snijders PJ, Heideman DA, Meijer CJ. Clinical implications of (epi)genetic changes in HPV-induced cervical precancerous lesions. Nat Rev Cancer. 2014; 14: 395-405.

89. Eden A, Gaudet F, Waghmare A, Jaenisch R. Chromosomal instability and tumors promoted by DNA hypomethylation. Science. 2003; 300: 455.

90. Szyf M, Targeti NG. DNA methylation in cancer. Ageing Res Rev. 2003; 2: 299-328.

91. Bachman KE. Histone modifications and silencing prior to DNA methylation of a tumor suppressor gene. Cancer Cell. 2003; 3: 89-95.

92. Brehm A, Nielsen SJ, Miska EA, McCance DJ, Reid JL, Bannister AJ, et al. The E7 oncoprotein associates with Mi2 and histone deacetylase activity to promote cell growth. EMBO J. 1999; 18: 2449-2458. 
93. Oh JK, Weiderpass E. Infection and cancer: Global distribution and burden of diseases. Ann Glob Health. 2014; 80: 384-392.

94. Lu Q, Ma DH, Zhao SP. DNA methylation changes in cervical cancers. Methods Mol Biol. 2012; 863: 155-176.

95. Ding DC, Chiang MH, Lai HC, Hsiung CA, Hsieh CY, Chu TY. Methylation of the long control region of HPV16 is related to the severity of cervical neoplasia. Eur J Obstet Gynecol Reprod Biol. 2009; 147: 215-220.

96. Hong D, Ye F, Lu W, Hu Y, Wan X, Chen Y, et al. Methylation status of the long control region of HPV 16 in clinical cervical specimens. Mol Med Rep. 2008; 1: 555-560.

97. Kalantari M, Chase DM, Tewari KS, Bernard HU. Recombination of human papillomavirus-16 and host DNA in exfoliated cervical cells: A pilot study of L1 gene methylation and chromosomal integration as biomarkers of carcinogenic progression. J Med Virol. 2010; 82: 311-320.

98. Turan T, Kalantari M, Calleja-Macias IE, Cubie HA, Cuschieri K, Villa LL, et al. Methylation of the human papillomavirus-18 L1 gene: A biomarker of neoplastic progression? Virology. 2006; 349: 175-183.

99. Turan T, Kalantari M, Cuschieri K, Cubie HA, Skomedal H, Bernard HU. High-throughput detection of human papillomavirus-18 L1 gene methylation, a candidate biomarker for the progression of cervical neoplasia. Virology. 2007; 361: 185-193.

100.Dueñas-González A, Lizano M, Candelaria M, Cetina L, Arce C, Cervera E. Epigenetics of cervical cancer. An overview and therapeutic perspectives. Mol Cancer. 2005; 4: 1-24.

101.Danam RP, Howell SR, Brent TP, Harris LC. Epigenetic regulation of O6-methylguanine-DNA methyltransferase gene expression by histone acetylation and methyl-CpG binding proteins. Mol Cancer Ther. 2005; 4: 61-69.

102.Snijders PJ, Steenbergen RD, Heideman DA, Meijer CJ. HPV-mediated cervical carcinogenesis: Concepts and clinical implications. J Pathol. 2006; 208: 152-164.

103. Yang HJ. Aberrant DNA methylation in cervical carcinogenesis. Chin J Cancer. 2013; 32: 42-48.

104.Rao Q, Shen Q, Zhou H, Peng Y, Li J, Lin Z. Aberrant microRNA expression in human cervical carcinomas. Med Oncol. 2012; 29: 1242-1248.

105.Zheng ZM, Wang X. Regulation of cellular miRNA expression by human papillomaviruses. Biochim Biophys Acta. 2011; 1809: 668-677.

106.Pedroza-Torres A, Lopez-Urrutia E, Garcia-Castillo V, Jacobo-Herrera N, Herrera LA, PeraltaZaragoza O, et al. MicroRNAs in cervical cancer: Evidences for a miRNA profile deregulated by HPV and its impact on radio-resistance. Molecules. 2014; 19: 6263-6281.

107. Ribeiro J, Sousa H. MicroRNAs as biomarkers of cervical cancer development: A literature review on miR-125b and miR-34a. Mol Biol Rep. 2014; 41: 1525-1531.

108. Sharma G, Dua P, Agarwal SM. A comprehensive review of dysregulated miRNAs involved in cervical Cancer. Curr Genomics. 2014; 15: 310-323.

109. Pereira PM, Marques JP, Soares AR, Carreto L, Santos MA. MicroRNA expression variability in human cervical tissues. PLoS One. 2010; 5: e11780.

110.Li Y, Wang F, Xu J, Ye F, Shen Y, Zhou J, et al. Progressive miRNA expression profiles in cervical carcinogenesis and identification of HPV-related target genes for miR-29. J Pathol. 2011; 224: 484-495.

111.Zeng K, Zheng W, Mo X, Liu F, Li M, Liu Z, et al. Dysregulated microRNAs involved in the progression of cervical neoplasm. Arch Gynecol Obstet. 2015; 292: 905-913. 
112. Cheung TH, Man KN, Yu MY, Yim SF, Siu NS, Lo KW, et al. Dysregulated microRNAs in the pathogenesis and progression of cervical neoplasm. Cell Cycle. 2012; 11: 2876-2884.

113. Bierkens M, Krijgsman O, Wilting SM, Bosch L, Jaspers A, Meijer GA, et al. Focal aberrations indicate EYA2 and hsa-miR-375 as oncogene and tumor suppressor in cervical carcinogenesis. Genes Chromosomes Cancer. 2013; 52: 56-68.

114.Bustin SA, Benes V, Garson JA, Hellemans J, Huggett J, Kubista M, et al. The MIQE guidelines: Minimum information for publication of quantitative real-time PCR experiments. Clin Chem. 2009; 55: 611-622.

115. Ma L, Young J, Prabhala H, Pan E, Mestdagh P, Muth D, et al. miR-9, a MYC/MYCN-activated microRNA, regulates E-cadherin and cancer metastasis. Nat Cell Biol. 2010; 12: 247-256.

116. Tilborghs S, Corthouts J, Verhoeven Y, Arias D, Rolfo C, Trinh XB, et al. The role of nuclear factorkappa B signaling in human cervical cancer. Crit Rev Oncol Hematol. 2017; 120: 141-150.

117. Wang YW, Chang HS, Lin CH, Yu WC. HPV-18 E7 conjugates to c-Myc and mediates its transcriptional activity. Int J Biochem Cell Biol. 2007; 39: 402-412.

118. Saavedra KP, Brebi PM, Roa JC. Epigenetic alterations in preneoplastic and neoplastic lesions of the cervix. Clin Epigenetics. 2012; 4: 1-7.

119. Mersakova S, Nachajova M, Szepe P, Kasajova PS, Halasova E. DNA methylation and detection of cervical cancer and precancerous lesions using molecular methods. Tumour Biol. 2016; 37: 23-27.

120.Lord CJ, Ashworth A. BRCAness revisited. Nat Rev Cancer. 2016; 16: 110-120.

121. Watkins JA, Irshad S, Grigoriadis A, Tutt AN. Genomic scars as biomarkers of homologous recombination deficiency and drug response in breast and ovarian cancers. Breast Cancer Res. 2014; 16: 211.

122.Pardini B, De Maria D, Francavilla A, Di Gaetano C, Ronco G, Naccarati A. MicroRNAs as markers of progression in cervical cancer: A systematic review. BMC Cancer. 2018; 18: 1-17.

123.Torres A, Torres K, Maciejewski R, Harvey WH. MicroRNAs and their role in gynecological tumors. Med Res Rev. 2011; 31: 895-923.

124. Kristeleit RS, Miller RE, Kohn EC. Gynecologic cancers: Emerging novel strategies for targeting DNA repair deficiency. Am Soc Clin Oncol Educ Book. 2016; 35: e259-e268.

125. Lorincz AT. Virtues and weaknesses of DNA methylation as a test for cervical cancer prevention. Acta Cytol. 2016; 60: 501-512.

126. Armstrong K, Kim JJ, Halm EA, Ballard RM, Schnall MD. Using lessons from breast, cervical, and colorectal cancer screening to inform the development of lung cancer screening programs. Cancer. 2016; 122: 1338-1342.

127. Srivastava S, Reid BJ, Ghosh S, Kramer BS. Research needs for understanding the biology of overdiagnosis in cancer screening. J Cell Physiol. 2016; 231: 1870-1875.

128. Colombo I, Kurnit KC, Westin SN, Oza AM. Moving from mutation to actionability. Am Soc Clin Oncol Educ Book. 2018; 38: 495-503.

129. Woodman CB, Collins SI, Young LS. The natural history of cervical HPV infection: Unresolved issues. Nat Rev Cancer. 2007; 7: 11-22.

130.Schiffman M, Doorbar J, Wentzensen N, de Sanjosé S, Fakhry C, Monk BJ, et al. Carcinogenic human papillomavirus infection. Nat Rev Dis Primers. 2016; 2: 1-20.

131.Ring KL, Garcia C, Thomas MH, Modesitt SC. Current and future role of genetic screening in gynecologic malignancies. Am J Obstet Gynecol. 2017; 217: 512-521. 
132. Mahdavi A, Monk BJ. Vaccines against human papillomavirus and cervical cancer: Promises and challenges. Oncologist. 2005; 10: 528-538.

133. Roden R, Wu TC. Preventative and therapeutic vaccines for cervical cancer. Expert Rev Vaccines. 2003; 2: 495-516.

134. Franconi R, Massa S, Paolini F, Vici P, Venuti A. Plant-derived natural compounds in genetic vaccination and therapy for HPV-associated cancers. Cancers (Basel). 2020; 12: 3101.

135.Palmer KE, Jenson AB, Kouokam JC, Lasnik AB, Ghim SJ. Recombinant vaccines for the prevention of human papillomavirus infection and cervical cancer. Exp Mol Pathol. 2009; 86: 224-233.

136. Bellone S, Pecorelli S, Cannon MJ, Santin AD. Advances in dendritic-cell-based therapeutic vaccines for cervical cancer. Expert Rev Anticancer Ther. 2007; 7: 1473-1486.

137. Baker GE, Tyring SK. Therapeutic approaches to papillomavirus infections. Dermatol Clin. 1997; 15: 331-340.

138. Ferrall L, Lin KY, Roden RBS, Hung CF, Wu TC. Cervical cancer immunotherapy: Facts and hopes. Clin Cancer Res. 2021. doi: 10.1158/1078-0432.CCR-20-2833.

139.Garg K, Karnezis AN, Rabban JT. Uncommon hereditary gynaecological tumour syndromes: Pathological features in tumours that may predict risk for a germline mutation. Pathology. 2018; 50: 238-256.

140. Harper DM, Franco EL, Wheeler C, Ferris DG, Jenkins D, Schuind A, et al. Efficacy of a bivalent L1 virus-like particle vaccine in prevention of infection with human papillomavirus types 16 and 18 in young women: A randomised controlled trial. Lancet. 2004; 364: 1757-1765.

141.Steller MA. Update on human papillomavirus vaccines for cervical cancer. Curr Opin Investig Drugs. 2002; 3: 37-47.

142.Steller MA. Cervical cancer vaccines: Progress and prospects. J Soc Gynecol Investig. 2002; 9: 254-264.

143. Hung CF, Monie A, Alvarez RD, Wu TC. DNA vaccines for cervical cancer: From bench to bedside. Exp Mol Med. 2007; 39: 679-689.

144.Vonka V, Hamsíková E. Vaccines against human papillomaviruses - a major breakthrough in cancer prevention. Cent Eur J Public Health. 2007; 15: 131-139.

145. Bayas JM, Costas L, Muñoz A. Cervical cancer vaccination indications, efficacy, and side effects. Gynecol Oncol. 2008; 110: S11-S14.

146. Lee SJ, Yang A, Wu TC, Hung CF. Immunotherapy for human papillomavirus-associated disease and cervical cancer: Review of clinical and translational research. J Gynecol Oncol. 2016; 27: e51.

147. Meserve EE, Nucci MR. Peutz-Jeghers syndrome: Pathobiology, pathologic manifestations, and suggestions for recommending genetic testing in pathology reports. Surg Pathol Clin. 2016; 9: 243-268.

148. Maguire RL, Vidal AC, Murphy SK, Hoyo C. Disparities in cervical cancer incidence and mortality: Can epigenetics contribute to eliminating disparities? Adv Cancer Res. 2017; 133: 129-156.

149. Eun TJ, Perkins RB. Screening for cervical cancer. Med Clin North Am. 2020; 104: 1063-1078.

150. Christensen ND. Emerging human papillomavirus vaccines. Expert Opin Emerg Drugs. 2005; 10: 5-19.

151. Available vaccines against HPV. In: HPV infections and cervical cancer. Epicentro. Epidemiology for public health. Rome: College of Health; 2015. Available from: 


\section{https://www.epicentro.iss.it/hpv/Vaccini-}

Disponibili\#: : :text=|\%20due\%20vaccini\%20ad\%20oggi,da\%20Hpv\%2016\%20e\%2018.

152. Mattiuzzi C, Lippi G. Current Cancer Epidemiology. J Epidemiol Glob Health. 2019; 9: 217-222.

153. National Screening Observatory. The numbers of screening. Report 2019 [Internet]. National Screening Observatory; 2020. Available from: http://www.osservatorionazionalescreening.it/content/i-numeri-degli-screening.

154. Comparetto C, Borruto F. Cervical cancer screening: A never-ending developing program. World J Clin Cases. 2015; 3: 614-624.

155. Sawaya GF, Smith-McCune K, Kuppermann M. Cervical cancer screening: More choices in 2019. JAMA. 2019; 321: 2018-2019.

156. Etzioni R, Urban N, Ramsey S, McIntosh M, Schwartz S, Reid B, et al. The case for early detection. Nat Rev Cancer. 2003; 3: 243-252.

157.Solomon D, Davey D, Kurman R, Moriarty A, O'Connor D, Prey M, et al. The 2001 Bethesda System: Terminology for reporting results of cervical cytology. JAMA. 2002; 287: 2114-2119.

158. Apgar BS, Zoschnick L, Wright TC. The 2001 Bethesda System terminology. Am Fam Physician. 2003; 68: 1992-1998.

159.Duffy MJ. Use of biomarkers in screening for cancer. EJIFCC. 2010; 21: 1-12.

160.Ditzian LR, David-West G, Maza M, Hartmann B, Shirazian T, Cremer M. Cervical cancer screening in low- and middle-income countries. Mt Sinai J Med. 2011; 78: 319-326.

161. Onyango CG, Ogonda L, Guyah B, Shiluli C, Ganda G, Orang'o OE, et al. Novel biomarkers with promising benefits for diagnosis of cervical neoplasia: A systematic review. Infect Agent Cancer. 2020; 15: 68.

162. Thomas LK, Bermejo JL, Vinokurova S, Jensen K, Bierkens M, Steenbergen R, et al. Chromosomal gains and losses in human papillomavirus-associated neoplasia of the lower genital tract - a systematic review and meta-analysis. Eur J Cancer. 2014; 50: 85-98.

163. Chrysostomou AC, Kostrikis LG. Methodologies of primary HPV testing currently applied for cervical cancer screening. Life (Basel). 2020; 10: 290.

164.Carse S, Bergant M, Schäfer G. Advances in targeting HPV infection as potential alternative prophylactic means. Int J Mol Sci. 2021; 22: 2201.

165. Dias TC, Longatto-Filho A, Campanella NC. Human papillomavirus genotyping as a tool for cervical cancer prevention: From commercially available human papillomavirus DNA test to next-generation sequencing. Future Sci OA. 2020; 6: FSO603.

166.Tota JE, Isidean SD, Franco EL. Defining benchmarks for tolerable risk thresholds in cancer screening: Impact of HPV vaccination on the future of cervical cancer screening. Int I Cancer. 2020; 147: 3305-3312.

167. Ntanasis-Stathopoulos I, Kyriazoglou A, Liontos M, A Dimopoulos M, Gavriatopoulou M. Current trends in the management and prevention of human papillomavirus (HPV) infection. J BUON. 2020; 25: 1281-1285.

168.Zheng R, Heller DS. High-risk human papillomavirus identification in precancerous cervical intraepithelial lesions. J Low Genit Tract Dis. 2020; 24: 197-201.

169. Mosele F, Remon J, Mateo J, Westphalen CB, Barlesi F, Lolkema MP, et al. Recommendations for the use of next-generation sequencing (NGS) for patients with metastatic cancers: A report from the ESMO Precision Medicine Working Group. Ann Oncol. 2020; 31: 1491-1505. 
170. Colombo I, Kurnit KC, Westin SN, Oza AM. Moving from mutation to actionability. Am Soc Clin Oncol Educ Book. 2018; 38: 495-503.

171. Rusan M, Li YY, Hammerman PS. Genomic landscape of human papillomavirus-associated cancers. Clin Cancer Res. 2015; 21: 2009-2019.

172. Roddy E, Chapman J. Genomic insights in gynecologic cancer. Curr Probl Cancer. 2017; 41: 8-36.

173.Selby K, Bartlett-Esquilant G, Cornuz J. Personalized cancer screening: Helping primary care rise to the challenge. Public Health Rev. 2018; 39: 1-8.

174. Atkinson A, Studwell C, Bejarano S, Castellón AM, Espinal JA, Deharvengt S, et al. Rural distribution of human papilloma virus in low- and middle-income countries. Exp Mol Pathol. 2018; 104: 146-150.

175. Hanselaar AG, Böcking A, Gundlach H, Palcic B, Markovic N, Patterson B, et al. Summary statement on quantitative cytochemistry (DNA and molecular biology): Task Force 8. Acta Cytol. 2001; 45: 499-501.

176. Introduction-Cervical screening program [Internet]. University of Trieste; 2017. Available from: https://moodle2.units.it/course/view.php?id=4388\#: :text=|l\%20carcinoma\%20del\%20collo\% 20CC,di\%20tutti\%20i\%20tumori\%20femminili\%20.

177.General Directorate for Prevention. National Oncological Commission. Guidelines concerning prevention, diagnosis, and assistance in oncology [Internet]. Available from: https://www.gazzettaufficiale.it/atto/serie generale/caricaArticolo?art.progressivo=1\&art.id Articolo=1\&art.versione $=1 \&$ art.codiceRedazionale $=001 \mathrm{~A} 3173 \&$ art.dataPubblicazioneGazzetta $=2001-05-$

02\&art.idGruppo=0\&art.idSottoArticolo1=10\&art.idSottoArticolo=1\&art.flagTipoArticolo=1.

178. Griesser H. Cytopathology - current trends. Verh Dtsch Ges Pathol. 2001; 85: 94-99.

179. Altiok S. Molecular markers in cervical cytology. Clin Lab Med. 2003; 23: 709-728.

180.Böcking A, Nguyen VQ. Diagnostic and prognostic use of DNA image cytometry in cervical squamous intraepithelial lesions and invasive carcinoma. Cancer. 2004; 102: 41-54.

181. Koeneman MM, Ovestad IT, Janssen EAM, Ummelen M, Kruitwagen RFPM, Hopman AH, et al. Gain of chromosomal region $3 q 26$ as a prognostic biomarker for high-grade cervical intraepithelial neoplasia: Literature overview and pilot study. Pathol Oncol Res. 2019; 25: 549557.

182. Mine KL, Shulzhenko N, Yambartsev A, Rochman M, Sanson GF, Lando M, et al. Gene network reconstruction reveals cell cycle and antiviral genes as major drivers of cervical cancer. Nat Commun. 2013; 4: 1806.

183. Martin CM, Kehoe L, Spillane CO, O'Leary JJ. Gene discovery in cervical cancer: Towards diagnostic and therapeutic biomarkers. Mol Diagn Ther. 2007; 11: 277-290.

184. Martin CM, Astbury K, McEvoy L, O’Toole S, Sheils O, O'Leary JJ. Gene expression profiling in cervical cancer: Identification of novel markers for disease diagnosis and therapy. Methods Mol Biol. 2009; 511: 333-359.

185. Wentzensen N, von Knebel Doeberitz M. Biomarkers in cervical cancer screening. Dis Markers. 2007; 23: 315-330.

186.von Knebel Doeberitz M. New molecular tools for efficient screening of cervical cancer. Dis Markers. 2001; 17: 123-128. 
187. Houldsworth J. FHACT: The FISH-based HPV-associated cancer test that detects nonrandom gain at four genomic loci as biomarkers of disease progression. Expert Rev Mol Diagn. 2014; 14: 921-934.

188.Gu W, Putral LN, Irving A, McMillan NA. The development and future of oligonucleotide-based therapies for cervical cancer. Curr Opin Mol Ther. 2007; 9: 126-131.

189.Gulliksen A, Karlsen F. Microchips for the diagnosis of cervical cancer. Methods Mol Biol. 2007; 385: 65-86.

190. Milde-Langosch K, Riethdorf S, Park TW. Natural course of HPV infection. Usefulness of HPV analysis in cervix diagnosis. Pathologe. 1999; 20: 15-24.

191.Gimenes F, Teixeira JJ, de Abreu AL, Souza RP, Pereira MW, da Silva VR, et al. Human leukocyte antigen (HLA)-G and cervical cancer immunoediting: A candidate molecule for therapeutic intervention and prognostic biomarker? Biochim Biophys Acta. 2014; 1846: 576-589.

192. Boone JD, Dobbin ZC, Straughn JM, Buchsbaum DJ. Ovarian and cervical cancer patient derived xenografts: The past, present, and future. Gynecol Oncol. 2015; 138: 486-491.

193. Ramzan M, Noor ul A, llyas S, Umer M, Bano S, Sarwar S, et al. A cornucopia of screening and diagnostic techniques for human papillomavirus associated cervical carcinomas. J Virol Methods. 2015; 222: 192-201.

194. Marcus PM, Freedman AN, Khoury MJ. Targeted cancer screening in average-risk individuals. Am J Prev Med. 2015; 49: 765-771.

195. Coutlée F, Mayrand MH, Roger M, Franco EL. Detection and typing of human papillomavirus nucleic acids in biological fluids. Public Health Genomics. 2009; 12: 308-318.

196. Bretthauer M, Kalager M. Principles, effectiveness and caveats in screening for cancer. Br J Surg. 2013; 100: 55-65.

197. Olusola P, Banerjee HN, Philley JV, Dasgupta S. Human papilloma virus-associated cervical cancer and health disparities. Cells. 2019; 8: 622.

198. Lee YY, Choi MC, Park JY, Suh DH, Kim JW. Major clinical research advances in gynecologic cancer in 2020. J Gynecol Oncol. 2021; 32: e53.

199. Chambers LM, Bussies P, Vargas R, Esakov E, Tewari S, Reizes O, et al. The microbiome and gynecologic cancer: Current evidence and future opportunities. Curr Oncol Rep. 2021; 23: 92.

200. Rodriguez NM. Participatory innovation for human papillomavirus screening to accelerate the elimination of cervical cancer. Lancet Glob Health. 2021; 9: e582-e583.

201. Medda A, Duca D, Chiocca S. Human papillomavirus and cellular pathways: Hits and targets. Pathogens. 2021; 10: 262.

202.Szymonowicz KA, Chen J. Biological and clinical aspects of HPV-related cancers. Cancer Biol Med. 2020; 17: 864-878.

203. Franco EL, Mahmud SM, Tota J, Ferenczy A, Coutlée F. The expected impact of HPV vaccination on the accuracy of cervical cancer screening: The need for a paradigm change. Arch Med Res. 2009; 40: 478-485.

204.Cao A. Genetic screening. XXI Century. In: Encyclopedia. Rome: Treccani; 2010. Available from: https://www.treccani.it/enciclopedia/screening-genetico \%28XXI-Secolo\%29/.

205.Smith RA, Mettlin CJ, Davis KJ, Eyre H. American cancer society guidelines for the early detection of cancer. CA Cancer J Clin. 2000; 50: 34-49.

206.Silverberg SG. Molecular diagnosis and prognosis in gynecologic oncology. Arch Pathol Lab Med. 1999; 123: 1035-1040. 
207. Crum CP. Contemporary theories of cervical carcinogenesis: The virus, the host, and the stem cell. Mod Pathol. 2000; 13: 243-251.

208. Okunade KS. Human papillomavirus and cervical cancer. J Obstet Gynaecol. 2020; 40: 602-608.

209. Ndifon CO, Al-Eyd G. Atypical squamous cells of undetermined significance. In: StatPearls [Internet]. Treasure Island (FL): StatPearls Publishing; 2021.

210. Chung SH, Woldenberg N, Roth AR, Masamed R, Conlon W, Cohen JG, et al. BRCA and beyond: Comprehensive image-rich review of hereditary breast and gynecologic cancer syndromes. Radiographics. 2020; 40: 306-325.

211.Shah UJ, Nasiruddin M, Dar SA, Khan MK, Akhter MR, Singh N, et al. Emerging biomarkers and clinical significance of HPV genotyping in prevention and management of cervical cancer. Microb Pathog. 2020; 143: 104131.

212.Pahlawanian AM, Norris VA, Jernigan AM, Morrell B, Morrell M, Nair N, et al. An update on screening and prevention for breast and gynecological cancers in average and high risk individuals. Am J Med Sci. 2020; 360: 489-510.

213. Hull R, Mbele M, Makhafola T, Hicks C, Wang SM, Reis RM, et al. Cervical cancer in low and middle-income countries. Oncol Lett. 2020; 20: 2058-2074.

214.Kremer WW, Steenbergen R, Heideman D, Kenter GG, Meijer C. The use of host cell DNA methylation analysis in the detection and management of women with advanced cervical intraepithelial neoplasia: A review. BJOG. 2021; 128: 504-514.

215. Malla R, Kamal MA. E6 and E7 oncoproteins: Potential targets of cervical cancer. Curr Med Chem. 2020. doi: 10.2174/0929867327666201111145546.

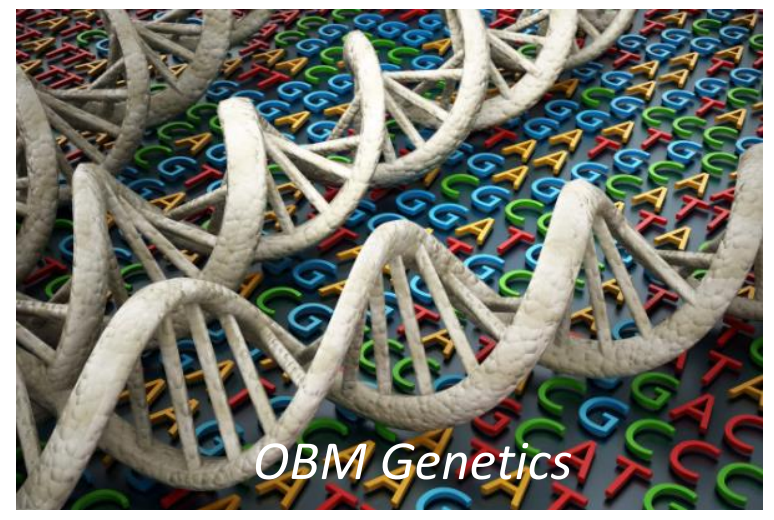

Enjoy OBM Genetics by:

1. Submitting a manuscript

2. Joining in volunteer reviewer bank

3. Joining Editorial Board

4. Guest editing a special issue

For more details, please visit:

http://www.lidsen.com/journals/genetics 